Document downloaded from:

http://hdl.handle.net/10251/62347

This paper must be cited as:

Moreno, JD.; Bonilla Salvador, MM.; Adam Martínez, JM.; Borrachero Rosado, MV.; Soriano Martinez, L. (2015). Determining corrosion levels in the reinforcement rebars of buildings in coastal areas. A case study in the Mediterranean coastline. Construction and Building Materials. 100:11-21. doi:10.1016/j.conbuildmat.2015.09.059.

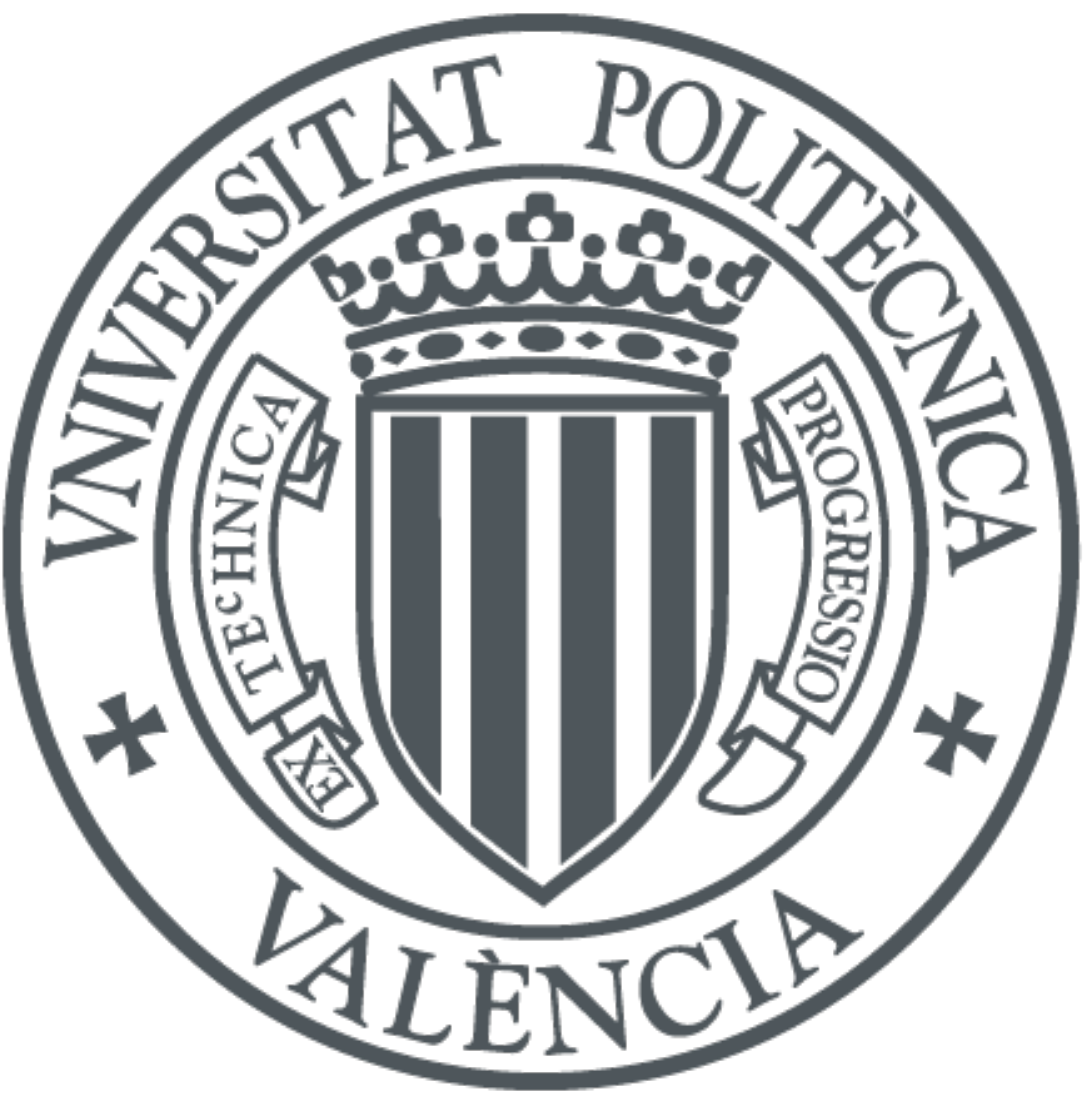

The final publication is available at

dx.doi.org/10.1016/j.conbuildmat.2015.09.059

Copyright Elsevier

Additional Information 


\title{
Determining corrosion levels in the reinforcement rebars of buildings in coastal areas. A case study in the Mediterranean coastline
}

\author{
José D. Moreno, MercedesBonilla, Jose M. Adam*, \\ M. VictoriaBorrachero, Lourdes Soriano \\ ICITECH, UniversitatPolitècnica de València. 46022 Valencia, Spain \\ *Corresponding author. Tel.: +34 963877562; fax: +34 963877568 \\ E-mail address: joadmar@cst.upv.es (J.M. Adam)
}

\section{ABSTRACT}

This paper describes a study of the damage caused by corrosion to the reinforcement rebars of a 40year old building used as a car park at a distance of 20 metres from the sea. The corrosion levels of the building's structural elements, including beams, joists and columns were analyzed by optical and electron microscopy. Carbonation depths and chloride contents (Vorhard method) of the concrete cover were measured in situ. EDX was used to analyze the condition of the reinforcement surfaces and the morphology and composition of the oxides. A high degree of corrosion was observed in all the above elements, carbonation had reached the depth of the reinforcement in all the samples studied, and the concrete chloride levels were far in excess of the recommended maximums. The study of the reinforcement rebars revealed different types of oxides of varying morphologies, compaction and colouring according to chloride content. A comparison with previous studies allowed us to verify the presence of crystals of at least akaganeite, lepidocrocite and goethite.

Key Words: Marine corrosion; Durability;Building; Oxide types; Reinforced concrete 


\section{Introduction}

The Valencia coastline has been a leading tourist region in Spain since the nineteen-sixties and its popularity has given rise to the massive construction of residential buildings in the area. Many of these have been raised close to beaches, where this was possible, at between 10 to 20 metres from the waterline. Being so close to the sea, the buildings are exposed to the marine environment and in many cases also to the direct effect of the marine aerosol.

The main cause of the loss of durability in coastal buildings is the corrosion of the reinforcement rebars due to the chloride ion effect [1], which is often found in combination with carbonation processes [2]. Both phenomena contribute to the destruction of the passive film on the surface of the reinforcementexisting in the steel surface protected to the corrosion.

Salt particles suspended in the marine atmosphere are deposited on the surface of the concrete and the chloride ions then penetrate to the interior, where there is a strong likelihood of them corroding the reinforcement. The rate of the deposit depends on the saline content of the sea breeze and is rapidly reduced with distance from the sealine. Some studies have shown that there are different concentration levels in the salt spray zone in relation to distance from the shore line, especially in the first $200 \mathrm{~m}$ [3]. The chloride ions build up faster than atmospheric carbon dioxide (which is responsible for carbonation of the concrete), so that the action of chlorides is usually the chief factor in the corrosion of reinforcement in this type of atmosphere, when the structure is exposed to a sea breeze.

The depassivating effect of chloride ions becomes apparent when a threshold value of chloride concentration is reached in the concrete. Factors that influence this threshold value include atmospheric conditions such as moisture content, the presence of oxygen, and period of exposure to the marine environment, as well as aspects related to the composition of the concrete, including: different conditions of the reinforcement passivation, water/cement ratio, type of cementitious matrix, and hydroxide content of the porous network [4,5].

Distance from the sea is an important factor in the quantity of salt particles deposited on a surface and therefore also in their reaching the reinforcement. In addition, the wetting-drying cycles of the concrete affect the content of chloride ions, which can be from 3 to 8 times higher when these cycles are absent [6]. 
Although there are many bibliographical references on different aspects of the durability of reinforced concrete in marine environments, most studies on corrosion in reinforced concrete structures were either carried out in the laboratory or samples were subjected to accelerated exposure in controlled environments. Also, few studies deal with concrete structures exposed in situ to long-term marine environments. To cite some examples: De la Fuente [7], Santana [8] and Castaño [9], among others, studied the effects of long-term exposure (13 years, 2 years and 14 months, respectively), under different atmospheric conditions, but on samples of steel; Poupard [10] studied reinforced concrete beams that had been in a tidal marine zone for a period of 40 years; Medeiros [6] studied the parameters that affect corrosion in the columns of a 37-storey building with two basements situated $700 \mathrm{~m}$ from the coastline.

In the marine environment, depassivation of the reinforcement can lead to the formation of an irregular layer of oxide on the steel/concrete interface. The thickness and composition of the products in this layer have been widely studied by various authors, all of whom agree that it is mostly composed of non-protective iron oxides and oxyhydroxides. Poupard et al. [10] state that the thickness increases with the degree of corrosion, varies between approximately 20 and $500 \mu$, and that its composition depends on the degree of damage it has sustained; for "low corroded" regions it is composed solely of magnetite $\left(\mathrm{Fe}_{3} \mathrm{O}_{4}\right)$, while "high-corroded" regions contain goethite $(\alpha-\mathrm{FeO}(\mathrm{OH}))$, maghemite $\left(\mathrm{Fe}_{2} \mathrm{O}_{3}\right)$ and akaganeite $\beta-\mathrm{FeO}(\mathrm{OH}, \mathrm{Cl})$.Oh et al [11] point out that when the same type of steel is exposed to different ambient conditions, the characteristics of the corrosion products vary in relation to different ambient conditions. However, they also found that certain corrosion products are always present, regardless of the environmental conditions and type of steel studied.

The location of different crystalline phases in the oxide layer has also been thoroughly studied; in particular for highly corroded steel, different authors found this layer to be composed of different sublayers [12,13]. Shiotani et al. [12] studied steel that had been exposed to a marine atmosphere for 27 years and after examining the samples by polarized optical microscopy, found that the internal zones appeared to be constituted mainly of magnetite and goethite, besides an amorphous substance, while the outer layer contained lepidocrocite $(\gamma-\mathrm{FeO}(\mathrm{OH}))$ and occasionally akaganeite. Duffo et al [13] in their work on a bar embedded in concrete that had been exposed for 65 years to an atmospheric environment found that the inner layer was formed chiefly by adherent non- 
products in the oxide layer due to goethite, magnetite or maghemite only occurs in the presence of carbonation $[10,13]$ but not when attacked by chlorides. Magnetite is developed in the vicinity of the steel surface where oxygen availability is lower $[7,14]$.

As a number of authors have pointed out $[10,14,15]$ lepidocrocite and magnetite are generally formed in the early stages of atmospheric corrosion. The lepidocrocite content usually diminishes with time, as it changes into goethite after prolonged exposure [15].

In the highly corroded areas, goethite is present in the oxide layer, especially in the external sublayer. Akaganeite becomes present in the oxide layer at high chloride concentrations [7,15-17]. Ma et al.[15] verified that the presence of $\mathrm{Cl}^{-}$and therefore of the akaganeite phase, is an indicator of high corrosion rates.

Crystal morphology depends on the conditions under which crystals are formed. Lepidocrocite is frequently found in the form of small crystalline globules (sandy crystals) or as fine plates (flowery structure) $[7,9,15]$. Goethite morphology usually has a globular structure known as cotton balls (semicrystalline goethite) connected by nest-like formations (nest morphology) or even by acicular structures (crystalline goethite). Magnetite is found in the form of dark flat regions, with hard-toidentify circular discs, while akaganeite can take the appearance of cotton balls or be rose-shaped [7]. As can be gathered from the above studies, the different crystal morphologies have a strong influence on their degree of compactness and therefore on their porosity and the ability of moisture and air to get inside [18].

The different morphologies of the iron oxides and oxyhydroxides found in corrosion affect not only compactness and porosity but also the volume of the layer, and so have different expansive effects on concrete. Many authors, e.g. Cascudo [19], pointed that iron oxides (II) and (III) have approximately twice the volume of the steel from which they proceed. In addition, if the oxides are hydrated (oxyhydroxides), the volume can be up to four times greater and could give rise to the formation of lepidocrocite, goethite or akaganeite, which would make fissures appear in the oxide layers themselves.

This paper studies the state of corrosion of the reinforcement rebars of different reinforced concrete structural elements: columns, beams and joists in a building situated $20 \mathrm{~m}$ from the edge of the sea after long-term exposure (45 years) to a marine atmosphere, including the identification of the type 
of attack suffered and the morphology of the corrosion products. The novel contribution of this work is that it shows the result of corrosion in situ in a real structure exposed to an aggressive marine environment for a long period and its correlation with the controlled atmospheric conditions described in the bibliography.

\section{Materials and methods}

\subsection{Description of the structural elements studied}

Specimens were taken for subsequent laboratory tests from a building in Cullera (Spain) that was being completely rebuilt and situated $20 \mathrm{~m}$ from the coastline (39¹0'51.6" $\left.\mathrm{N} 0^{\circ} 13^{\prime} 09.1^{\prime \prime} \mathrm{W}\right)$. The building structure was composed of reinforced concrete frames with floor slabs and the tests were carried out on beams, joists and columns.

The building in question had been put up in 1968 and was used as a car-park. The façades were of non-waterproof lattice-work construction, which allowed the salt spray to get inside and on windy days the walls could even be splashed by sea-water spray from high waves.

\subsection{Characteristics of the local environment}

Cullera is in the Mediterranean climatic region. Average annual temperature is $17^{\circ} \mathrm{C}$, ranging from $11.2^{\circ}$ in January to $25.9^{\circ}$ in July. Annual rainfall is $475 \mathrm{~mm}$ per square metre [20]. The prevailing wind is from the east-northeast at an average speed of $6.5 \mathrm{kph}$. The temperature of the sea water varies between $12^{\circ} \mathrm{C}$ in winter to $24-25^{\circ} \mathrm{C}$ in August and September.

The building is beside the coast at $16 \mathrm{~m}$ metres from the water line and $10 \mathrm{~m}$ above sea level in uneven rocky terrain. The entire building is exposed to a greater or lesser degree to the marine environment and in stormy conditions the sea spray is blown into the building through the lattice walls.

\subsection{Samples}

This paper contains the results of the tests on the most severely corroded samples. The information obtained from optical (SM) and electron (SEM) microscopy pertains to specimens taken from 
columns in the outer wall and floor beams and joists that had been subjected to natural wettingdrying cycles

The columns had a square $0.30 \times 0.30 \mathrm{~m}^{2}$ cross section, $12 \mathrm{~mm}$ diameter reinforcement at each corner with a $30 \mathrm{~mm}$ cover and $6 \mathrm{~mm}$ diameter stirrups each $0.30 \mathrm{~m}$. The beams had $0.30 \times 0.40 \mathrm{~m}$ rectangular cross sections, $16 \mathrm{~mm}$ diameter rebars, two in the upper and two in the lower section, with a $30 \mathrm{~mm}$ cover and $6 \mathrm{~mm}$ diameter stirrups every $0.30 \mathrm{~m}$. The floor joists were of prestressed concrete with three steel wires in the lower section. All the elements studied were severely affected by corrosion.

\subsection{Method}

\subsubsection{Visual Inspection}

In the specimens described in this paper, spalling is observed in the concrete cover due to corrosion of the reinforcement rebars. The least severe case described here is a column (Fig.1) in which the cover can be seen to have separated from the rebars, which are severely corroded and have lost cross-sectional area (Figs.1 and 2). In one of the beams the spalling is seen to have been due to the corrosion of the rebars (Fig.3).

The most severe case of corrosion was found in a joist (Figs. 4 and 5) which can be seen to have lost its entire concrete cover from the bottom section. The prestressing wires are highly corroded in a large part of the zone affected by oxidation and have almost completely disappeared. It is worth mention here the possibility of stress corrosion cracking in wires.

\subsubsection{Carbonation depth and chloride content}

Carbonation depth was measured directly by normalized test with $1 \%$ phenolphthalein dissolved in alcohol [21]. The concrete cover was measured to the depth of the reinforcement at different sites and carbonation depth was measured with calipers.

The chloride content of concrete samples was measured in the laboratory in accordance with the procedure described in the UNE-EN-112010 "Corrosion of concrete reinforcement steel. Determining chloride content of in-service concrete" [22]. This technique is based on the Volhard 
method (back titration by silver nitrate and ammonium thiocyanate in the presence of iron (III) salts as indicator).

\subsubsection{Analysis of rebar samples and characterization of corrosion products}

General samples were taken from the concrete cover and rebars of the elements studied to analyze the concrete-reinforcement interface and the morphology of the oxide layers by optical microscopy (magnifications of from 8x to 80x using a Leica MZ APO Stereoscopic Microscope and scanning electron microscopy (SEM2 JEOL Model JSM6300) with backscattered electron detector (BSE) or X-Rays (EDX),as required. The sample images were magnified between 20x and 500x. SEM was used at magnifications of up to 6000x to identify oxide types in both the reinforcement-concrete interface and in rebars. The analysis of the elements present was by EDX.

\section{Results and discussion}

\subsection{Analyses of carbonation depth, chloride content, and pore volume and density}

Carbonation depth in the elements studied in situ by the phenolphthalein test is seen in all cases to be equal to or greater than the thickness of the cover. The chloride ion concentration measured in the entire concrete samples was found to be between $0.60 \%$ and $0.85 \%$ respect to concrete. Although the maximum chloride ion value below which rebars are not considered to be at risk of depassivation depends on many variables, a chloride ion content of $0.4 \%$ of cement by weight or $0.05 \%$ of the weight of non-carbonated concrete is generally accepted as a reliable limit [1]. By this criterion, the concentration found in the samples studied is clearly too high.

\subsection{Analyses of rebar samples and characterization of corrosion products}

Figs. 6, 7 and 8 show 8x magnified optical microscope images of samples taken from a joist steel wire with pitting corrosion (Fig.6) plus a section from the column reinforcement (Figs.7 and 8), previously treated with nitric acid to eliminate impurities. Fig. 6 shows the typical pitting and reduced cross-sectional area of wires subjected to a marine environment. Fig. 7 shows a rebar sample taken from the corroded section of a column in which the steel-oxide interface can be clearly seen. Also visible are corrosion stains inside the steel itself. Fig. 8 shows the area of the reinforcement affected by pitting. 
238 Fig. 9 shows salt deposits embedded in the interior of the steel-oxide interface in contact with the

239

240

241

242

243

244

245

246

247

248

249

250

251

252

253

254

255

256

257

258

259

260

261

262

263

264

265

266

267

268

269

270

steel, which appears to be the start of a pitting process due to high chloride content. Fig. 10 is a $25 \mathrm{x}$ magnification of the steel-oxide interface in which cracks can be seen in the interior of the corroded zone. Fig. 11 is a 25x magnified image of a corroded area with black, yellow and brown patches, indicating the presence of different corrosion products [14]. The black patch can be attributed to the presence of magnetite [23] and wustite [24], while the yellow and brown are due to the presence of iron oxyhydroxides, mainly akaganeite, lepidocrocite and goethite.

The SEM study of pitting between 20x (Fig.12) and 150x (Figs.13 and 14) shows the presence of crystals due to salt deposits around and inside the pitting. The crystals composition it shows in Table 1.

In order to study the composition of the pitting in the rebars, bearing in mind that they had been exposed to the marine environment for 45 years, a microstructural analysis of the oxide layer was carried out, as seen in Fig. 15, which shows corroded zones of different colours. The same effect was noted in the pitting seen through the optical microscope (Figs.7-11). Table 2 gives the atomic\% composition of the analysed elements by zone. A mapping study was also carried out to detect the regions with the highest (lighter colour) and lowest (darker colour) presence of iron (Fig.15b), oxygen (Fig.15c) and chlorine (Fig.15d). These images helped us to determine the thickness of the pitting, the different types of oxide present and the zone with the highest concentration of chloride ions.

In the SEM image shown in Figure 15a, five different coloured zones can be clearly identified. Zone 1 is that of non-corroded steel. Zones $2-5$ are made up of different oxide compositions, seen as variations in the greyish tones and compactness related to different concentrations of chloride. Zone 2 is the deepest, at the rebar-oxide interface, where the chlorine ion content is lowest and most compact. Zones 3 and 4 have a more porous oxide layer with a higher chlorine content (slightly lower in Zone 3). Zone 5 contains the outside layer, again more compact and with a lower concentration of chlorides than the intermediate zone. It should be emphasized that chloride ions together with a large number of cracks were found in all the pitted regions, undoubtedly caused by the different volumes of the oxides present. The atomic \% O/Fe ratio is equal to 1 in the deepest and most compact part of Zone 2, indicating that the type of oxide in this layer is $\mathrm{FeO}$ contaminated by chlorides. All the other layers have an $\mathrm{O} / \mathrm{Fe}$ ratio $>1$, which implies that they contain iron 
oxyhydroxides. Following Koleva [25], in both cases the formation of iron oxy-chloride complexes is suggested.

Figs. 16 and 17 contain SEM maps of a detail of the rebar/oxide interface with the notable presence of chloride ions. In Fig. 16, an agglomeration of salts can be seen, evidently due to the absence of iron (Fig.16b) and oxygen (Fig.16c) in this zone, which indicates a high concentration of chlorine (Fig.16d). Here again numerous cracks can be seen in the oxide layer. In this case the chloride ion content in the rebar/oxide interface is very high and there are chlorine crystals encrusted on the metal surface (Fig.16d).

Fig. 17a shows a non-compact band in the steel (left)/oxide (right) interface that facilitates the free diffusion of chlorides through the metal surface. Note the high chloride ion content in both interface zones (Fig.17d). This shows the aggressiveness (attack) of the chloride ions and the growing depth of the pitting. The presence of chloride ions in the interior of the metal zone is also evident in the scan shown in Fig. 18.

Figs. 19 and 20 show some details of the different morphologies of the oxides in one of the pitted zones. In both SEM images the oxide on the lower right-hand side has a more porous structure with the presence of more open zones; the oxide on the right-hand side has a more compact structure. Note once again the presence of numerous cracks due to the different expansion rates of the oxides (Fig.21).

As regards the nature of the oxides present in the corroded parts of the different structural members, a distinction has to be made between those observed by SEM in column reinforcement and in the joists. The oxides in the former are generally amorphous, and crystalline formations are only found in the zones with the highest chloride concentrations at high magnifications (6000x) (Fig.22a). The oxides found in the joists show a range of more stable and with a higher degree of crystallinity forms, identified as iron and chlorine oxyhydroxides(Fig.23). The higher tendency of joists to corrosion due to a thinner concrete cover, the characteristics of prestessing steel wires (smaller diameter, internal loads, surface, etc.) and freer access of oxygen and chlorine to the reinforcement, explain their higher corrosion levels. In some cases the steel can dissolve within the concrete to such an extent that it completely disappears. 
In Fig. 23 the morphology of the oxides in the rebar samples taken from the column and joist are shown in SEM images. The layers are in general highly porous, as can be expected from steel subjected to a marine environment for an extended period. Acicular morphologies can be observed in the form of cotton balls and rosettes. Even though the shape of the oxide surface can vary significantly for different types of exposure [13], in a comparison with the bibliography $[7,15,16]$ it seems clear that the shapes are due to the presence of akaganeite $(\beta-\mathrm{FeOOH})$.

Fig. 24 shows images of some oxides with open-structured crystals present in the corrosion layer of the joist wire, previously treated with $\mathrm{HNO}_{3}$ to eliminate traces of mortar and non-adhering impurities. References in the bibliography identify these as lepidocrocite crystals $(\gamma-\mathrm{FeOOH})$ typically found in highly corroded samples $[7,13,18]$.

Typical goethite $(\alpha-\mathrm{FeOOH})$ formations can be seen in Fig.25a. According to the literature, these crystals are usually found together with magnetite $\left(\mathrm{Fe}_{3} \mathrm{O}_{4}\right)$ in the type of formations seen inFig.25b. The EDX analysis indicates the presence of $\mathrm{FeO}$ oxides in the darkest and most compact zone of the pitting/steel interface (see Table 3 andFig.26). This could be attributed to the formation of wustite, a phenomenon which has apparently not been found in previous studies.

\section{Conclusions}

Many of the studies on corrosion in reinforced concrete structures have either been carried out in laboratories or the samples have been subjected to accelerated exposure under controlled conditions. Little in-depth research has been done in situ on the damage caused to these structures by long term exposure to aggressive environments, however, the present paper deals with corrosion damage to an actual building exposed to the effects of a marine environment for a period of 45 years.

The presence of high concentrations of chloride ions in the concrete cover of columns and joists in the building was confirmed by the Volhard method, which in tests gave mean $\mathrm{Cl}^{-}$content values of $0.7 \%$ in the concrete. It was also confirmed that the concrete cover had been completely carbonated and had penetrated to the reinforcement. 
Inspection by optical microscope revealed deep pitting in the reinforcement rebars, which in some cases was accompanied by salt sediments in and around the corroded areas even after being treated with $\mathrm{HNO}_{3}$.

SEM images showed the presence of various types of oxides with different chloride ion contents in different coloured areas, with morphologies related to oxide porosity and compactness. High chloride contents were found in areas in which the oxides had a more porous and fragmented structure.

A range of diverse crystalline structures was also found, including: the characteristic cotton ball and rosette shapes of akaganeite, in both column and joist reinforcements, in samples seriously affected by chloride corrosion. Goethite and open-structured porous lepidocrocite were found in samples from highly corroded joists. The EDX analysis revealed crystals whose atomic \% Fe/O ratio was equal to 1 , suggesting the presence of $\mathrm{Fe} 0$ type wustite or similar.

\section{References}

[1] Angst U, Elsener B, Larsen CK, Vennesland O. Critical Chloride content in reinforced concrete, a review. Cement and Concrete Research 2009; 39: 1122-1138.

[2] Liu R, Jiang L, Xu J, Xiong C,Song Z. Influence of carbonation on chloride-induced reinforcement corrosion in simulated pore solution. Construction and Building Materials 2014; 56: $16-20$

[3] Meira GR, Padaratz IJ, Alonso C, Andrade C. Effect of distance from sea on chloride aggressiveness in concrete structures in Brazilian coastal site". Materiales de Construcción 2003; 53;271-272.

[4] Meira GR, Andrade C, Vilar EO,Nery KD. Analysis of chloride threshold from laboratory and field experiments in marine atmosphere zone. Construction and Building Materials 2014; 55: 289-298.

[5] Cheewaket T, Jaturapitakkul C, Chalee W. Initial corrosion presented by chloride threshold penetration of concrete up to 10 years-result under marine site. Construction and Building Materials 2012; 37:693-698.

[6] Medeiros MHF,Gobbi A, Reus GC, Helene P. Reinforced concrete in marine environment. Effect of wetting and drying cycles, height and positioning in relation of the seashore. Construction and Building Materials 2013; 44: 452-457. 
[7] De la Fuente D, Díaz I, Simancas J, Chico B, Morcillo M. Long-term atmospheric corrosion of mild steel. Corrosion Science 2011; 53: 604-617.

[8] Santana Rodríguez JJ., Santana Hernández FJ,González González, JE. XRD and SEM studies of the layer of corrosion products for carbon steel in various different environment in the province of Las Palmas. Corrosion Science 2002;44: 2425-2438.

[9] Castaño JG, Botero CA, Restrepo AH, Agudelo EA, Correa E, Echeverría F. Atmosphericcorrosion of carbonsteel in Colombia.Corrosion Science 2010; 52: 216-223.

[10] Poupard O, L'Hostis V, Catinaud S, Petre-Lazar I. Corrosion damage diagnosis of a reinforced concrete beam after 40 years natural exposure in marine environment. Cement and ConcreteResearch 2006; 36: 504-520.

[11] Oh SJ, Cook DC, Townsend HE, Atmospheric corrosion of different steels in marine, rural and industrial environment. Corrosion Science 1999;41: 1687-1702.

[12] Shiotani K, Tanimoto W, Maeda C, Kawabata F, Amano K.Analysis for Structure of rust layer formed on weathering steel bridge for bare use exposed in coastal industrial zone for 27 years. Corrosion Engineering 2000; 49(2), 67-71.

[13] Duffó GS, Morris W, Raspini I, Saragovi C. A study of steel rebars embedded in concrete during 65 years. Corrosion Science 2004; 46: 2143-2157.

[14] Misawa T, Kyuno T, Suetaka W, Shimodaira S. The mechanism of atmospheric rusting and the effect of $\mathrm{Cu}$ and $\mathrm{P}$ on the rust formation of low alloy steels. Corrosion Science 1971; 11(1): 3548.

[15] Ma Y, Li Y, Wang F. Corrosion of low carbon steel in atmospheric environments of different chloride content. Corrosion Science 2009; 51:997-1006.

[16] Antunes, RA, Costa I, Araújo de Faria DL. Characterization of Corrosion products formed don steels in the first month of atmospheric exposure. Materials Research 2003; 3(6): 403-408.

[17] ZitrouE, Nikolau J, Tsakiridis PE, Papadimitrou GD. Atmospheric corrosion of steel reinforcing bars produced by various manufacturating processes. Construction and Building Materials 2007; 21: 1161-1169.

[18] Dillmann P, Mazaudier F, Hoerlé S. Advances in understanding atmospheric corrosion of iron. I. Rust characterization of ancient ferrous artefacts exposed to indoor atmospheric corrosion. Corrosion Science 2004; 46: 1401-1429.

[19] Cascudo O. O controle da corrosão de armaduras em concreto - inspeção e técnicas eletroquímicas. Co-edição, São Paulo: Ed. PINI ,Goiânia: Ed. UFG, 1997. [in Portuguese]

[20] AEMET. Agencia Estatal de Metereología, www.aemet.es; 2015 
403

404

405

406

407

408

409

410

411

412

413

414

415

416

417

418

419

420

421

422

423

424

425

426

427

428

429

430

431

432

433

434

435

436

[21] UNE-EN 14630 (2007) Determinación de la Profundidad de carbonatación en un hormigón endurecido por el método de la fenoftaleína. AENOR. Madrid; 2007. [in Spanish]

[22] UNE 112010. Corrosion of concrete reinforcement steel. Chloride determination for in-service concrete. AENOR. Madrid; 2010.

[23] Alvedaño R, Ortega N. Characterization of concrete cracking due to corrosion of reinforcement in different environment. Construction and Building Materials 2011; 25: 630-637.

[24] www.mindarg.org

[25] KolevaDA, Hu J, Fraaij ALA, Stroeven P, Boshkov N, De Wit JHW. Quantitative characterization of steel/cement paste interface microstructure and corrosion phenomena in mortars suffering from chloride attack.Corrosion Science 2006; 48: 4001-4019.

(1) 


\section{Figure captions and Tables}

438

439

440

441

442

443

444

445

446

447

448

449

450

451

452

453

454

455

456

457

458

459

460

461

462

463

464

465

466

467

468

469

Fig.1. Spalling in cover of column

Fig.2. Corroded rebars in column

Fig.3. Spalling in beam cover

Fig.4. Spalling in joist cover

Fig.5. Loss of concrete and broken wires

Fig.6. Joist wire with pitting corrosion

Fig.7. Section of column rebar with pitting corrosion

Fig.8. Area of rebar affected by pitting

Fig.9. Detail of pitting with a crust of saline particles

Fig.10. Pitting with cracks due to different oxide composition

Fig.11. Different morphologies of oxides in pitting

Fig.12. Joist wire with pitting corrosion

Fig.13. Salt deposits on the surface of a pitted zone

Fig.14. Salt deposits inside a pitted zone

Fig.15. Microstructural analysis of oxide layer on rebar. a) Different oxide morphologies and identification of analyzed zones; b) mapping of the presence of iron; c) mapping of the presence of oxygen; d) mapping of the presence of chlorine.

Fig. 16. Detail of the oxide-steel interface in corroded area. a) SEM image; b) mapping of the iron content; c) mapping of the oxygen content; d) mapping of the chlorine content.

Fig. 17. Detail of rebar (left)/oxide (right) interface of pitted area. a) SEM image 150x; b) mapping of the iron content; c) mapping of the oxygen content; d) mapping of the chlorine content.

Fig.18. Scan of steel/oxide interface. The figure on the right shows a detail of the relative contents of the elements studied

Fig.19. Morphology of oxides in a corroded zone

Fig.20. Morphology of oxides in a corroded zone

Fig. 21. Detail of cracks showing different oxide expansion rates

Fig.22. Morphology of oxides in pitting of column reinforcement. a) Crystalline formations found in zones with highest concentration of chloride ions; b) formations in zones with lowest concentrations of chloride ions.

Fig.23. Morphology of oxides in column rebars and joist wire

Fig.24. Morphology of oxides in joist wire 
470 Fig.25.Formations of oxides in rebars. a) Presence of magnetite and goethite b) typical goethite 471 crystals

472 Fig.26. Morphology and EDX analysis of $\mathrm{FeO}$ in joist wire

475 Table 1. EDX analysis of salt deposits on the pitting shown in Figure 13 (arrow)

476 Table 2. Atomic \% of elements Fe, $\mathrm{O}$ and $\mathrm{Cl}$ by EDX (* composition of rebar without allowing for 477 the error due to the $\mathrm{C}$ of the sample holder used in the analysis)

478 Table 3. EDX analysis of $\mathrm{FeO}$ in joist wire 
Table 1. EDX analysis of salt deposits on the pitting shown in Figure 13 (arrow)

\begin{tabular}{l|ll}
\hline Element & Weight\% & Atomic\% \\
O K & 39.25 & 63.90 \\
Na K & 5.66 & 6.41 \\
Mg K & 0.25 & 0.26 \\
Al K & 1.49 & 1.44 \\
Si K & 2.42 & 2.25 \\
P K & 0.13 & 0.11 \\
S K & 1.04 & 0.84 \\
Cl K & 4.46 & 3.28 \\
K K & 1.19 & 0.79 \\
Ca K & 0.73 & 0.47 \\
V K & 0.03 & 0.01 \\
Mn K & 0.24 & 0.11 \\
Fe K & 43.12 & 20.12 \\
Totals & 100.00 & \\
\hline
\end{tabular}

Table 2. Atomic \% of elements Fe, $\mathrm{O}$ and $\mathrm{Cl}$ by EDX (* composition of rebar without allowing for the error due to the $\mathrm{C}$ of the sample holder used in the analysis)

\begin{tabular}{lllll}
\hline Zone & Fe & $\mathrm{O}$ & $\mathrm{Cl}$ & An. Atoms \\
\hline 1 & $87^{*}$ & & & $\mathrm{C}, \mathrm{Mn}$ \\
2 & 48.99 & 49.02 & $1.94-0.68$ & $\mathrm{Si}, \mathrm{S}$ \\
3 & 44.55 & 44.55 & 10.77 & \\
4 & $39.66-39.57$ & $44.63-42.22$ & $17.13-13.73$ & Si,S,Ca \\
5 & $43.80-45.21$ & $48.70-48.92$ & $5.45-3.24$ & Si/S,Na \\
\hline
\end{tabular}

Table 3. EDX analysis of FeO in joist wire

\begin{tabular}{lllll}
\hline Element & Weight\% & Atomic\% & Compd\% & Formula \\
\hline Fe K & 77.73 & 50.00 & 100.00 & FeO \\
O & 22.27 & 50.00 & & \\
Totals & 100.00 & & & \\
\end{tabular}




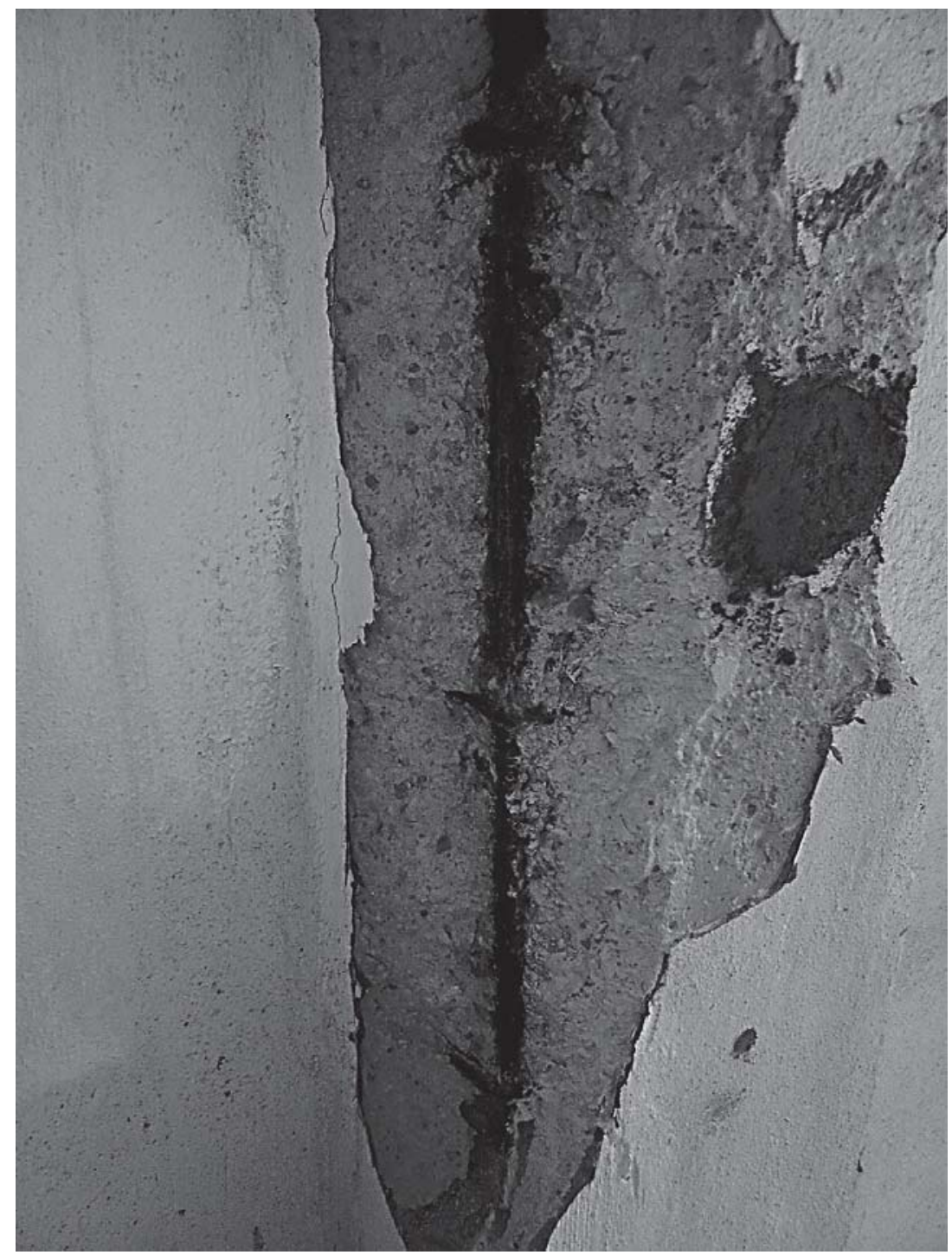

Fig.1. Spalling in cover of column 


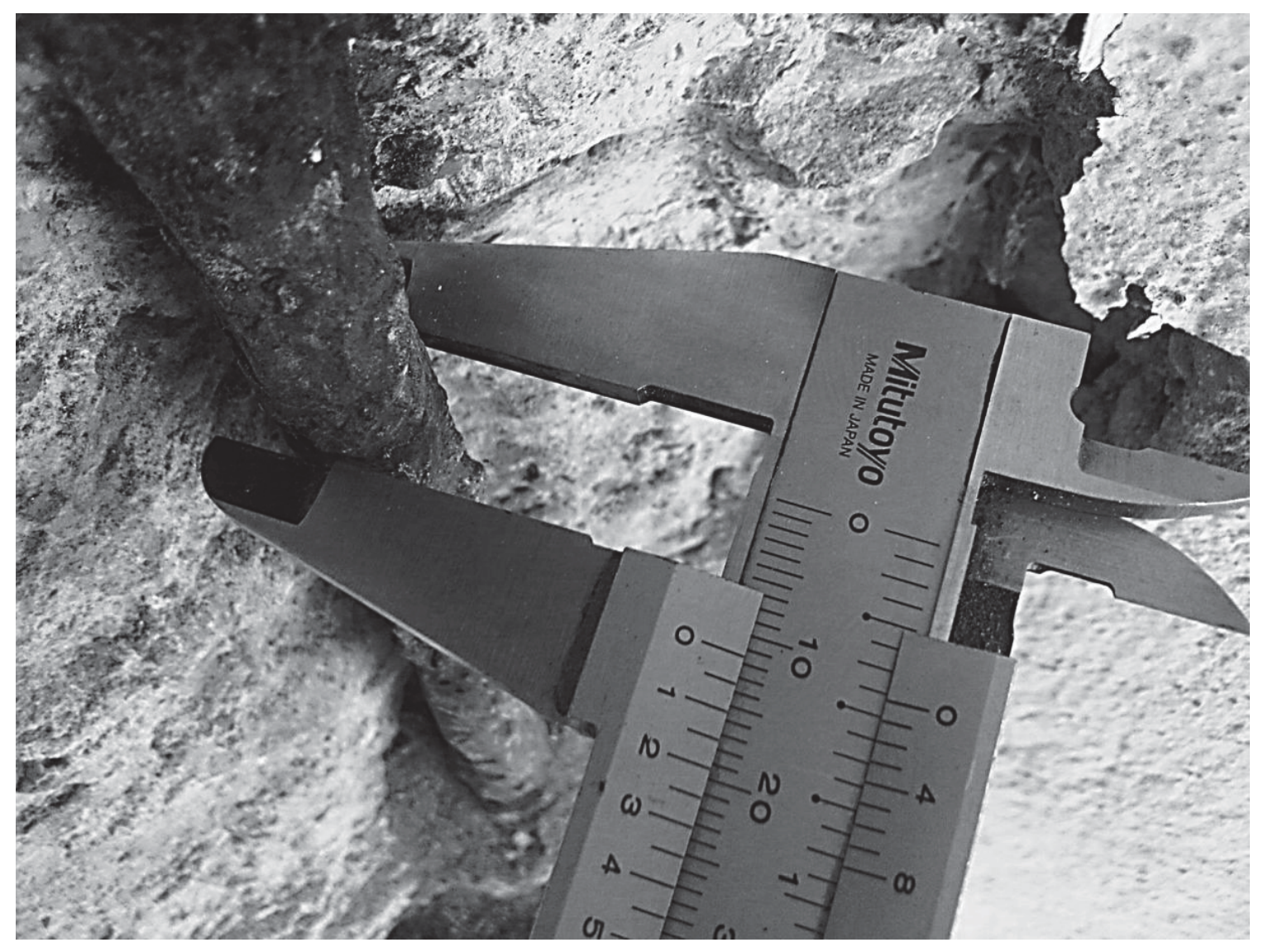

Fig.2. Corroded rebars in column 


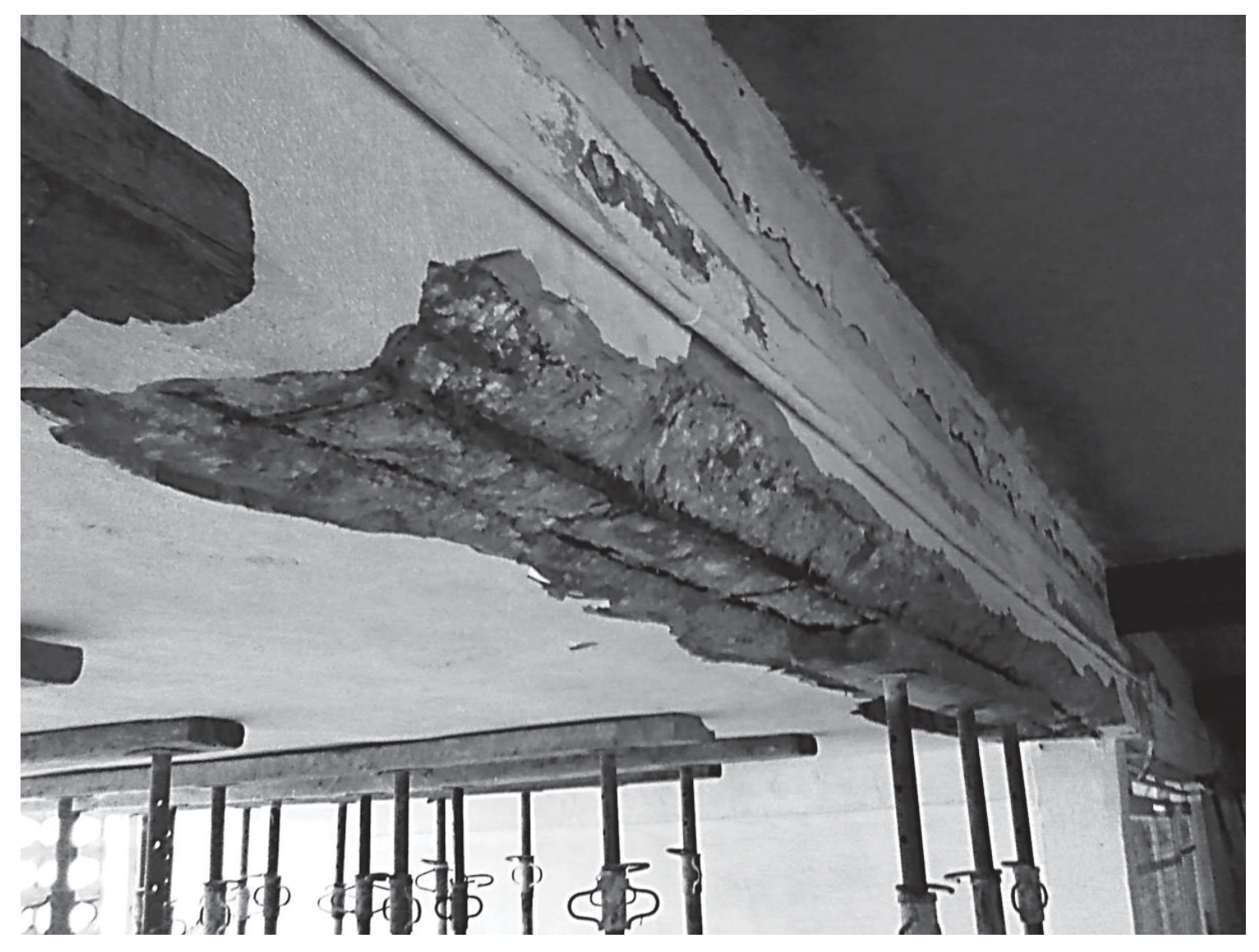

Fig.3. Spalling in beam cover 


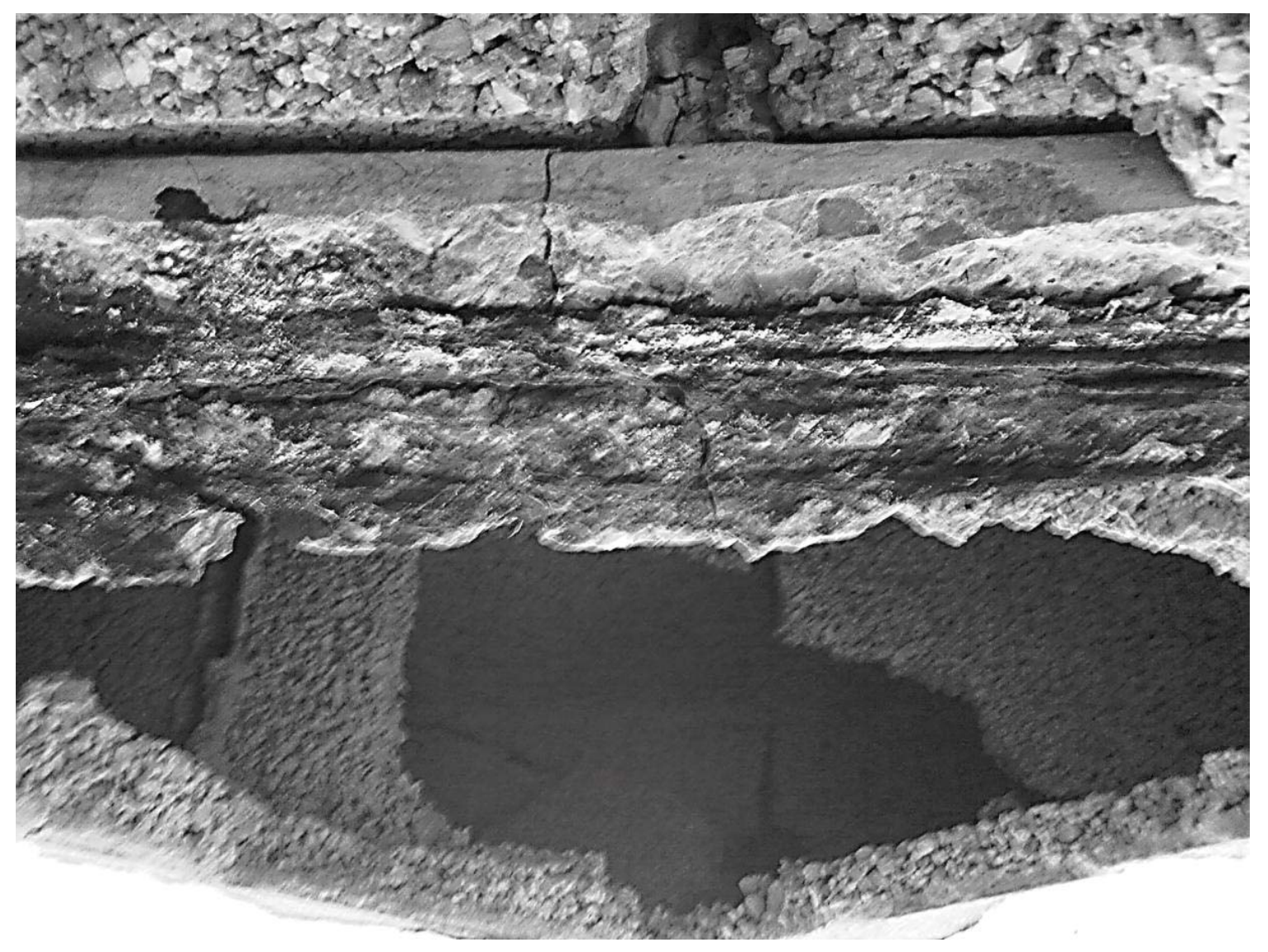

Fig.4. Spalling in joist cover 


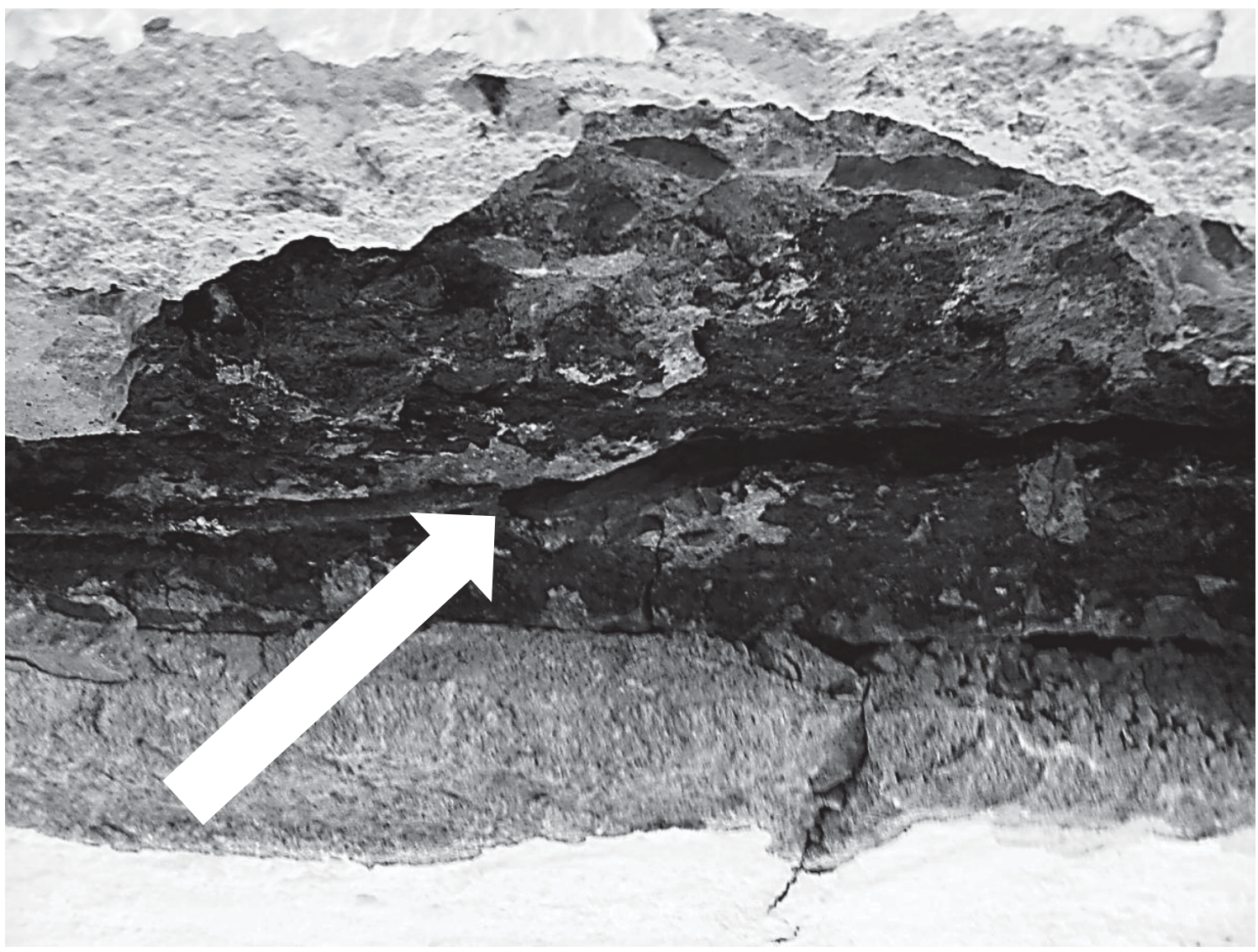

Fig.5. Loss of concrete and broken wires 


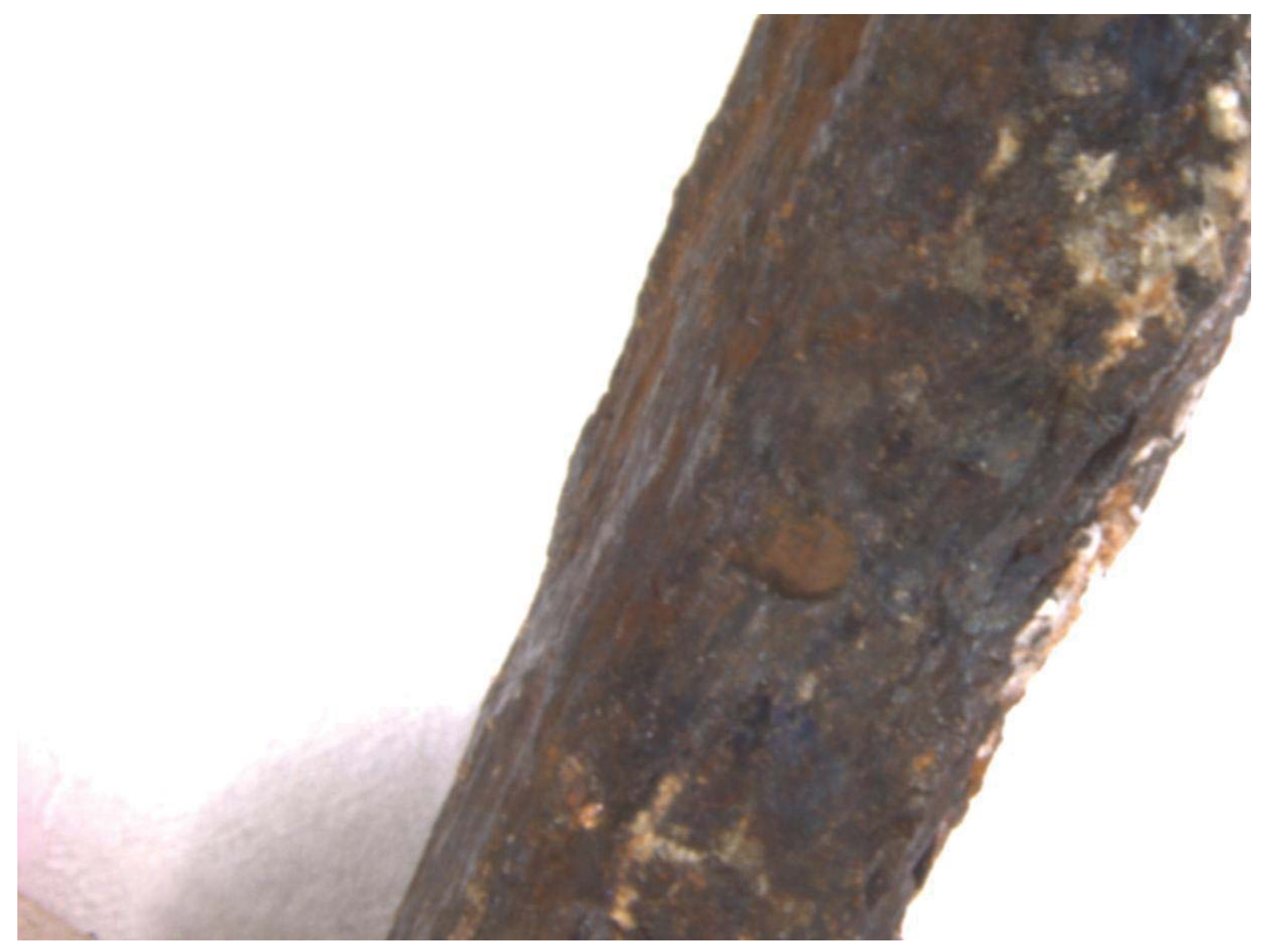

Fig.6. Joist wire with pitting corrosion 


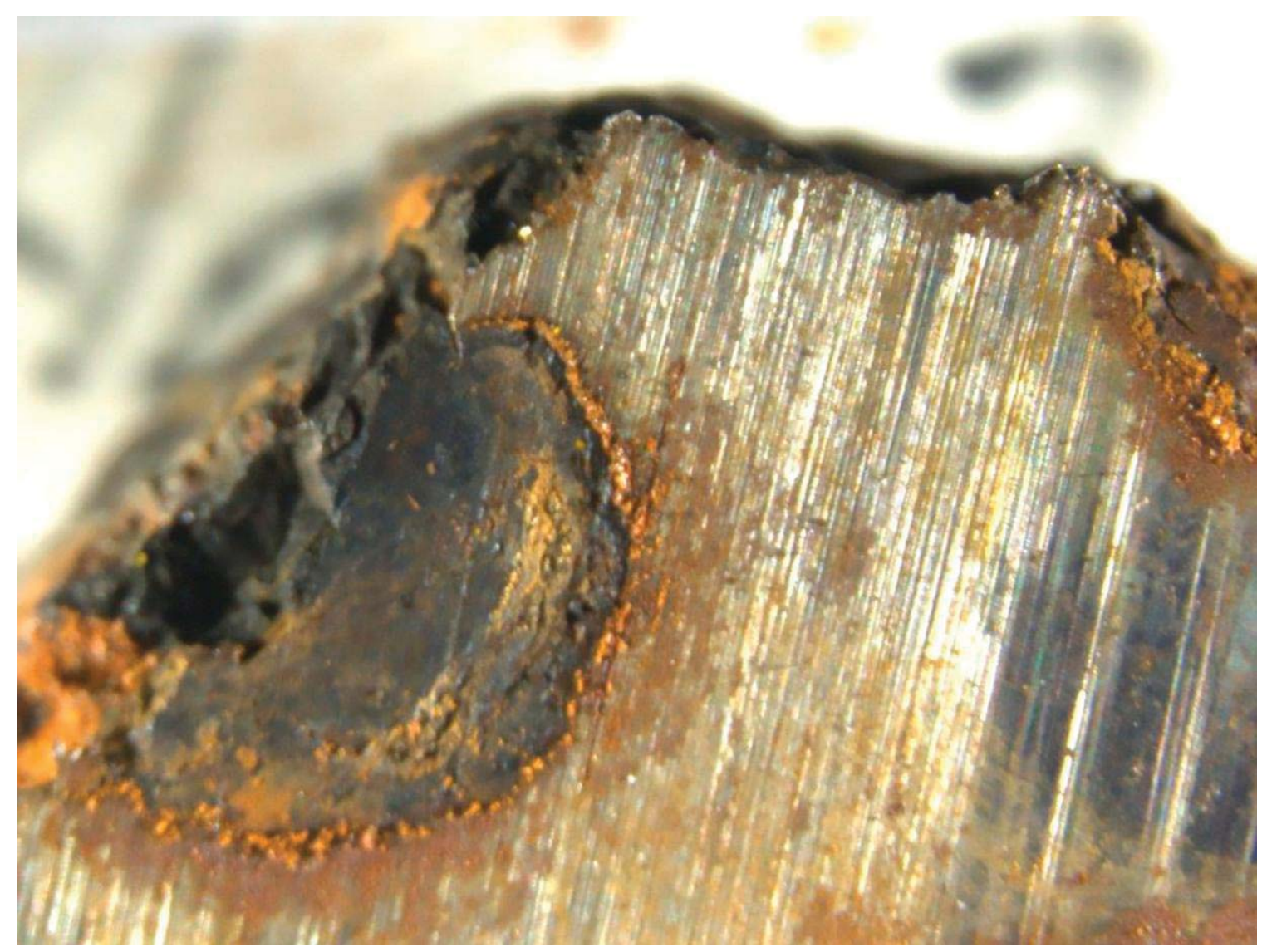

Fig.7. Section of column rebar with pitting corrosion 


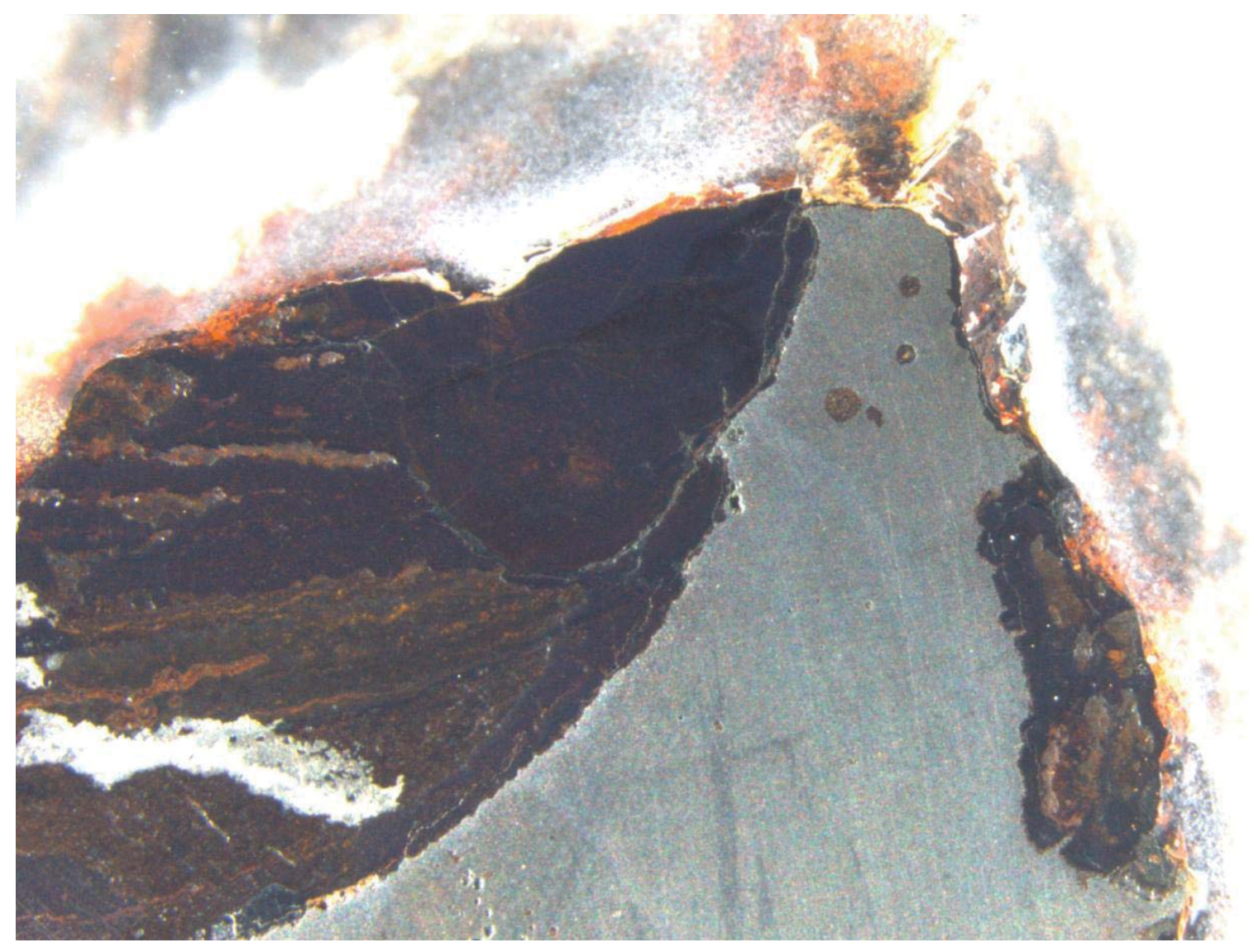

Fig.8. Area of rebar affected by pitting 


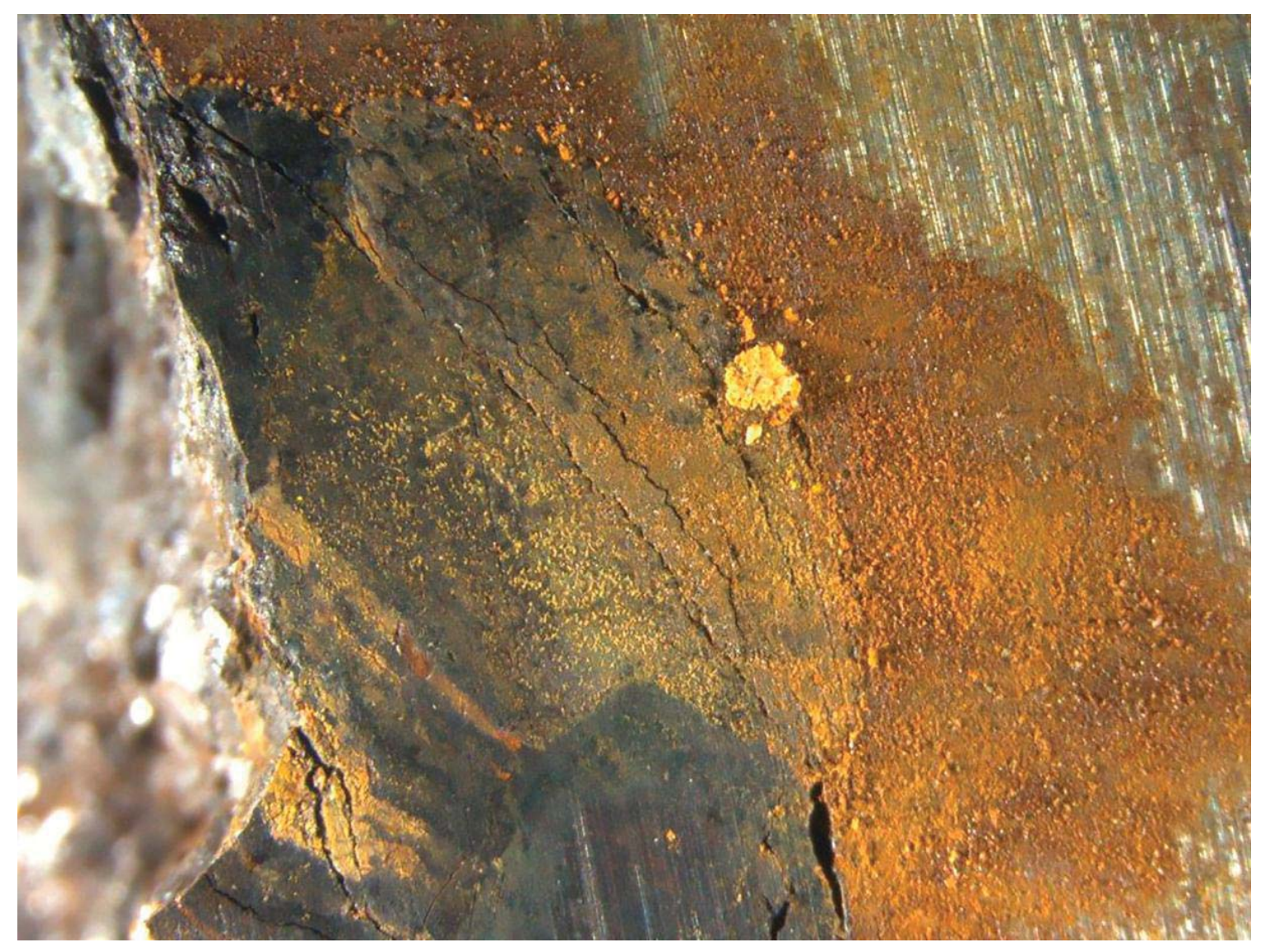

Fig.9. Detail of pitting with a crust of saline particles 


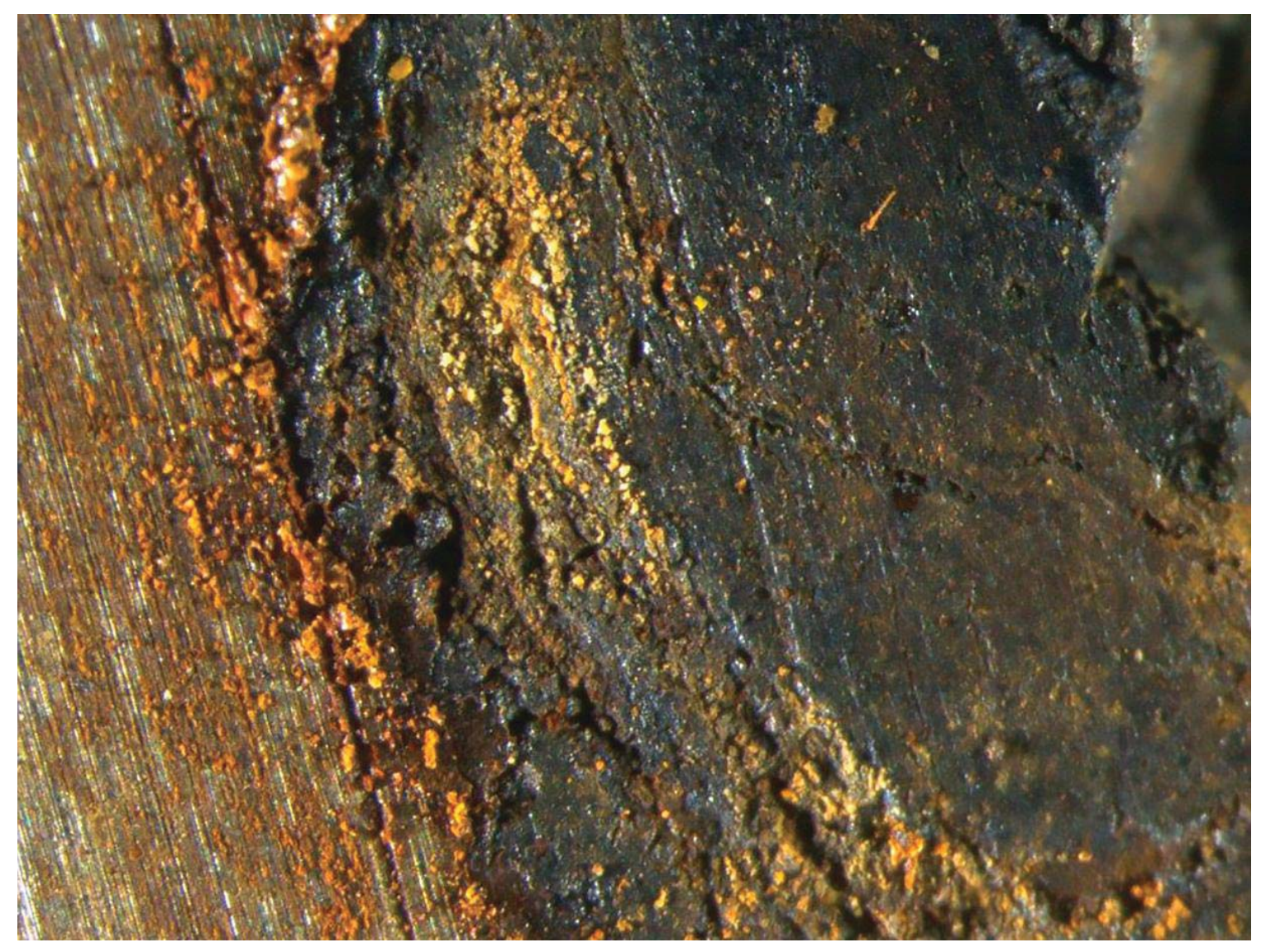

Fig.10. Pitting with cracks due to different oxide composition 


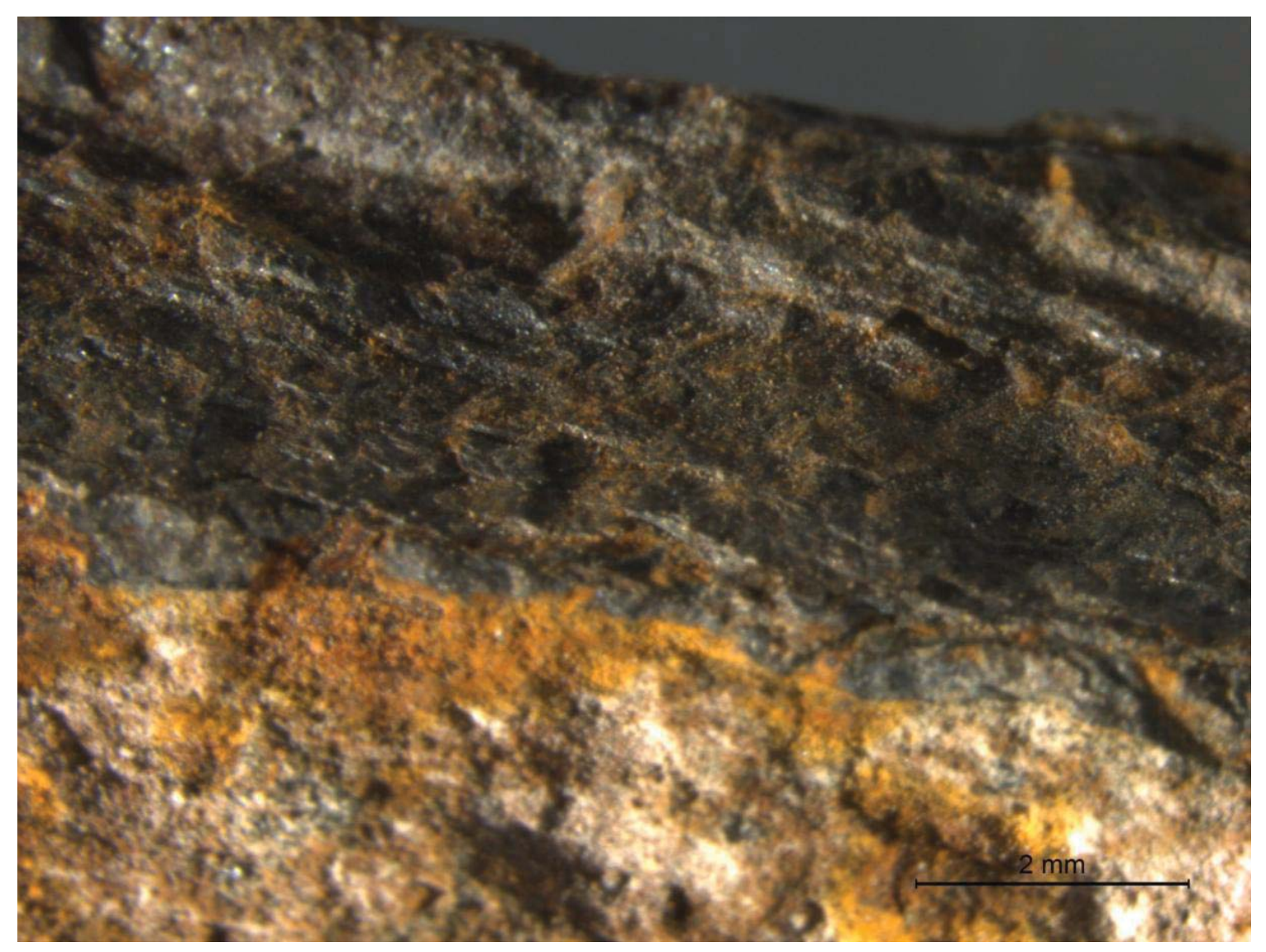

Fig.11. Different morphologies of oxides in pitting 


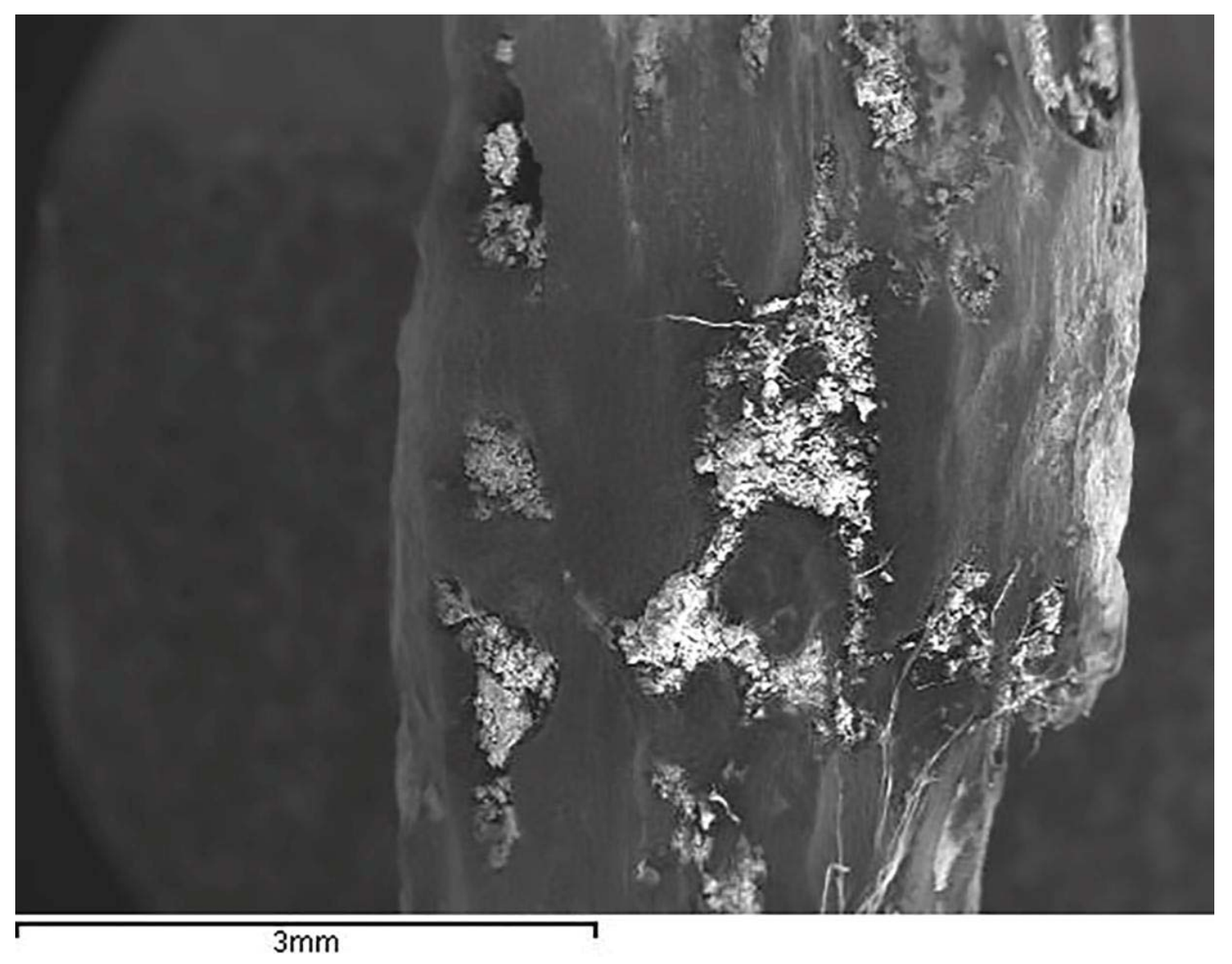

Fig.12. Joist wire with pitting corrosion 


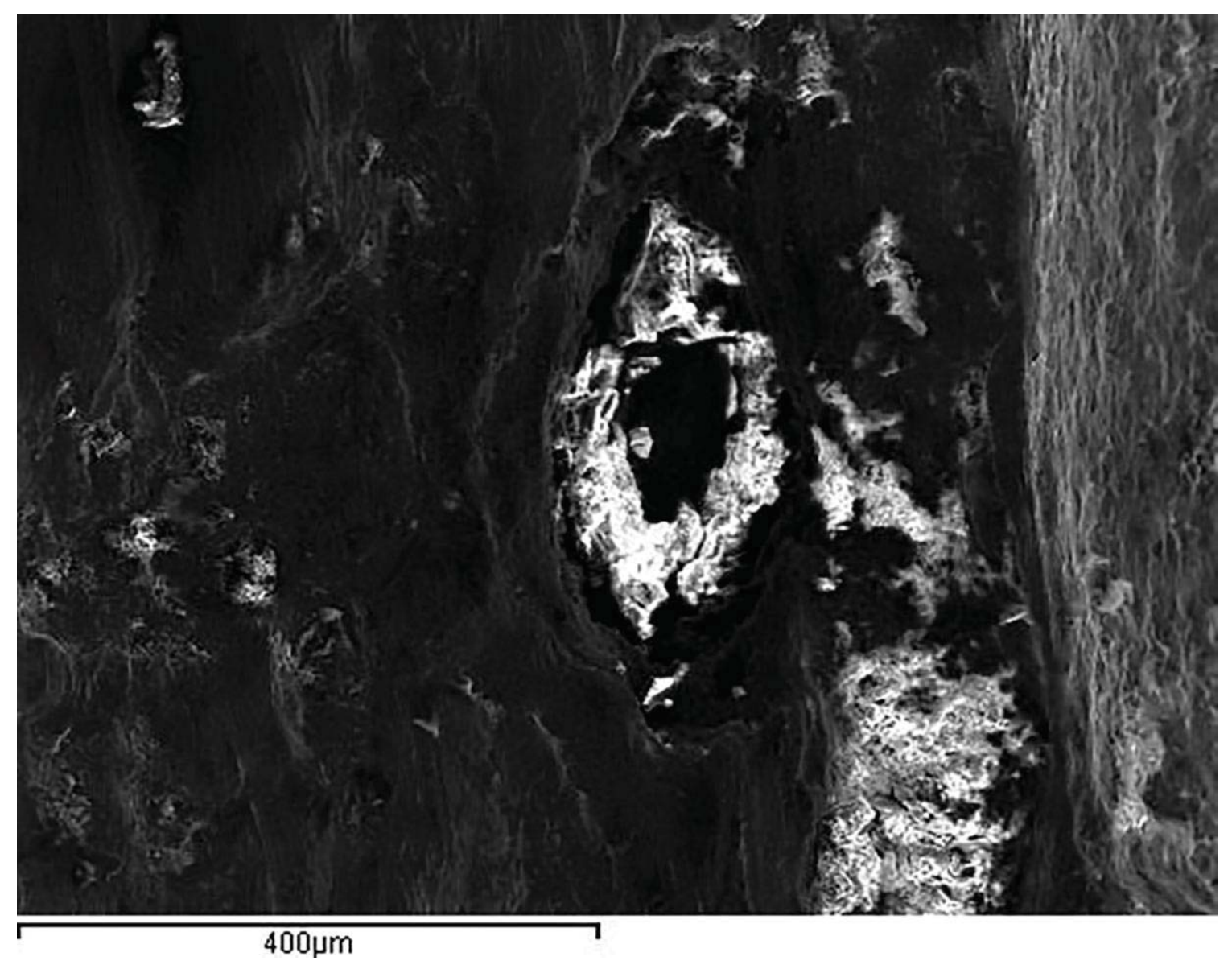

Fig.13. Salt deposits on the surface of a pitted zone 


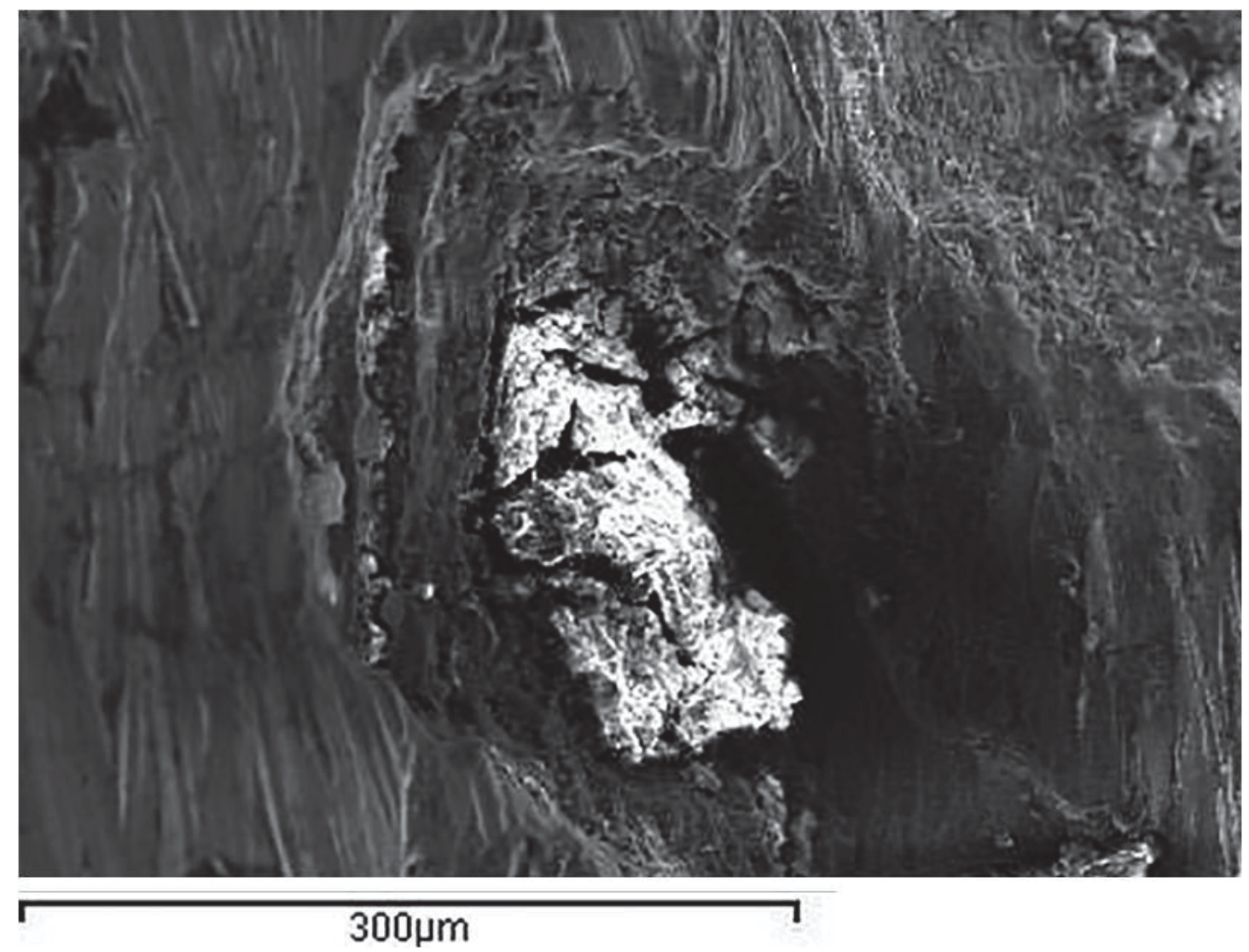

Fig.14. Salt deposits inside a pitted zone 

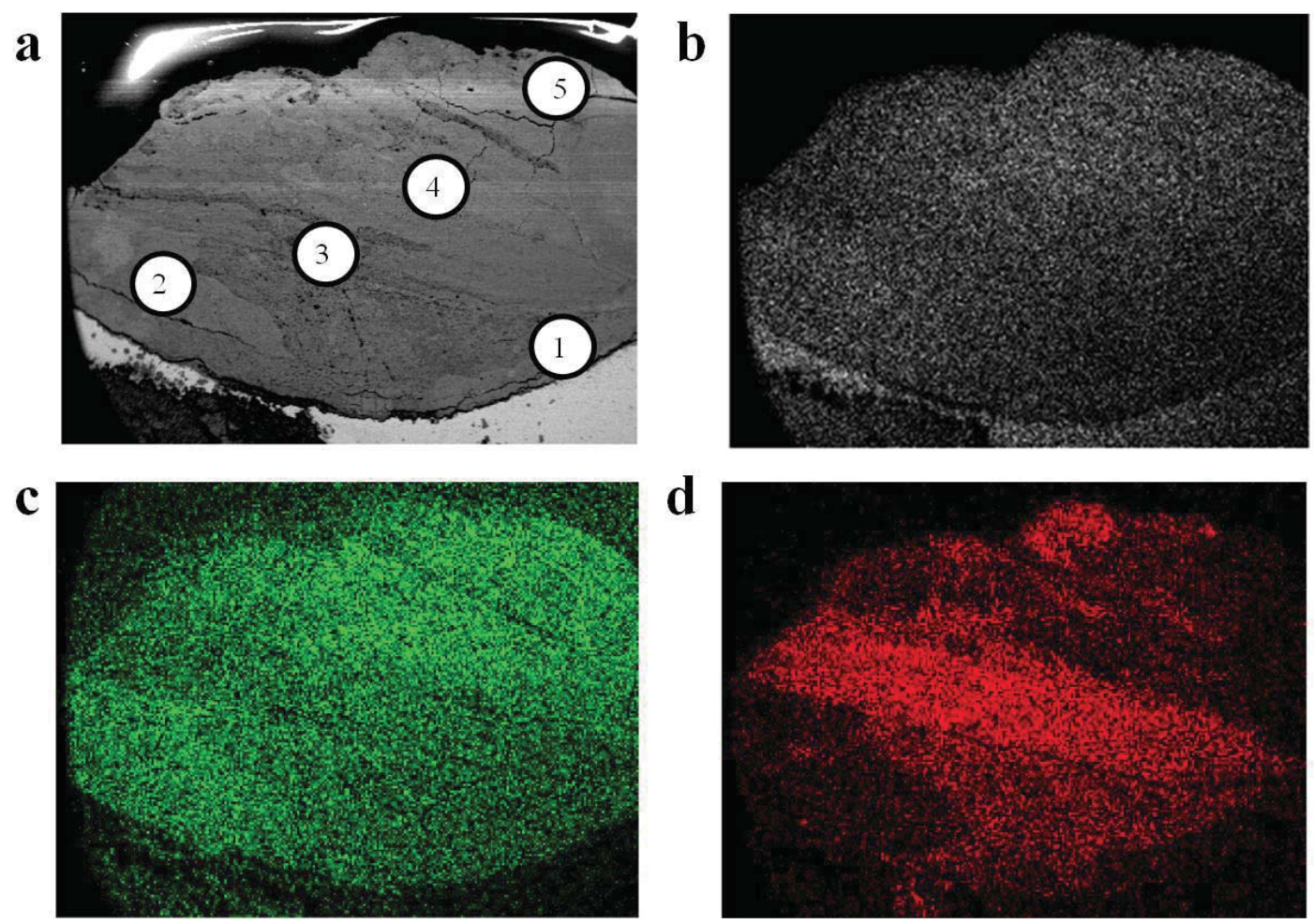

Fig.15. Microstructural analysis of oxide layer on rebar. a) Different oxide morphologies and identification of analyzed zones; b) mapping of the presence of iron; c) mapping of the presence of oxygen; d) mapping of the presence of chlorine. 

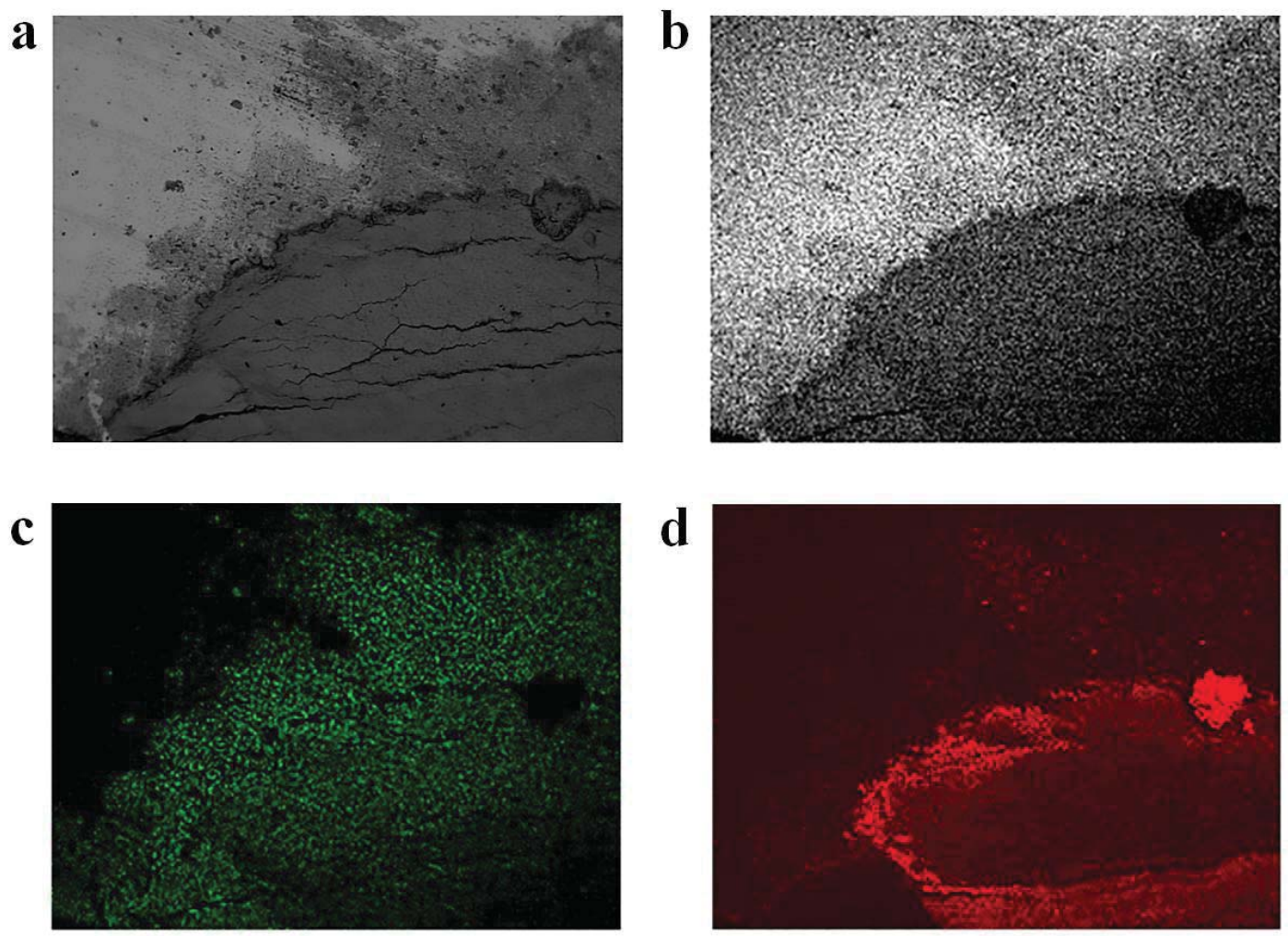

Fig 16. Detail of the oxide-steel interface in corroded area. a) SEM image; b) mapping of the iron content; c) mapping of the oxygen content; d) mapping of the chlorine content 
$\mathbf{a}$

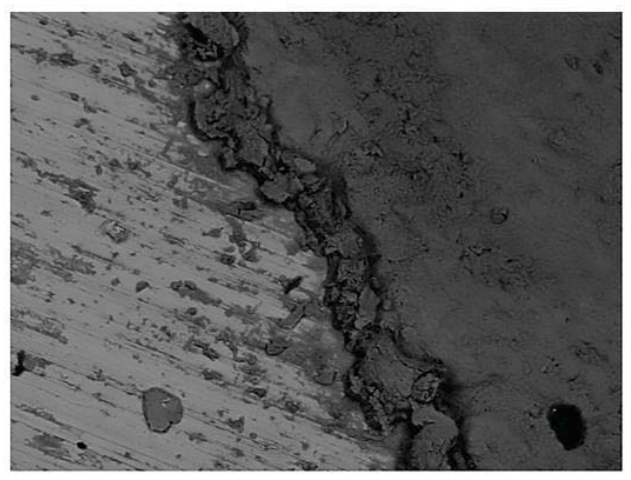

b

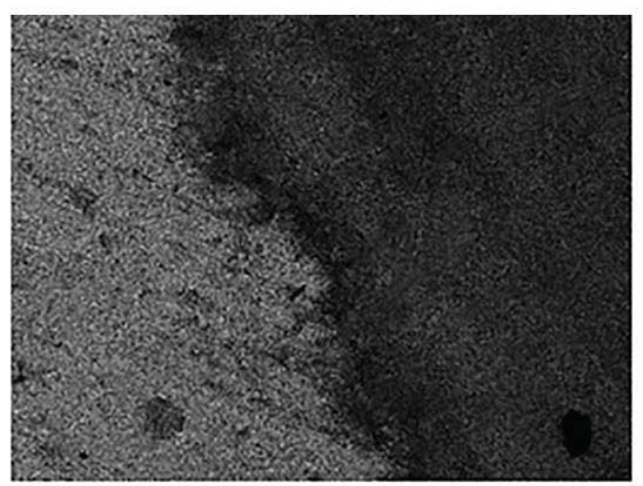

c

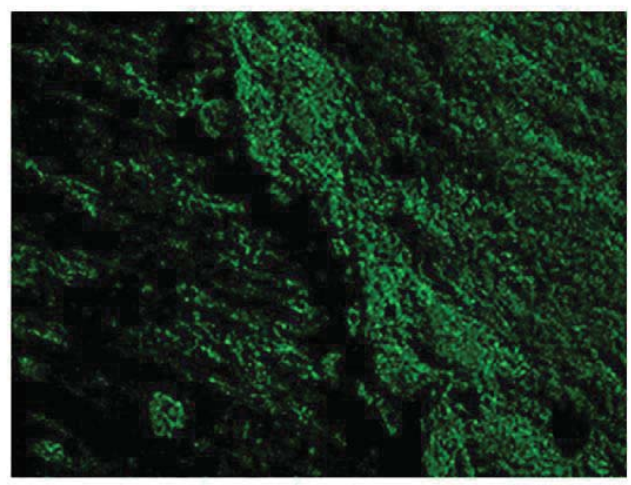

d

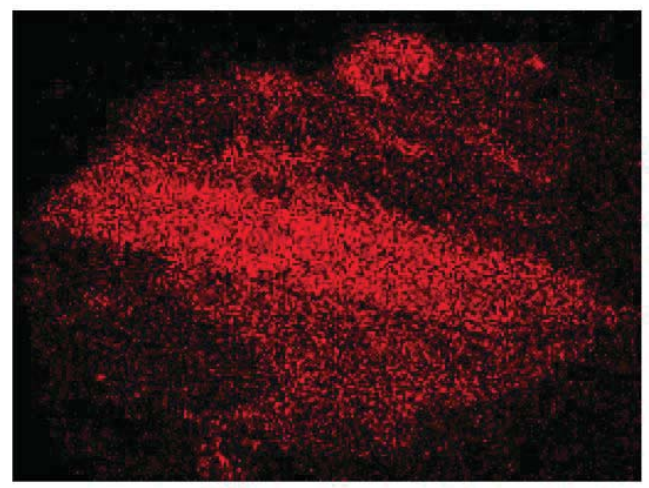

Fig. 17. Detail of rebar (left)/oxide (right) interface of pitted area. a) SEM image 150x; b) mapping of the iron content; c) mapping of the oxygen content; d) mapping of the chlorine content. 

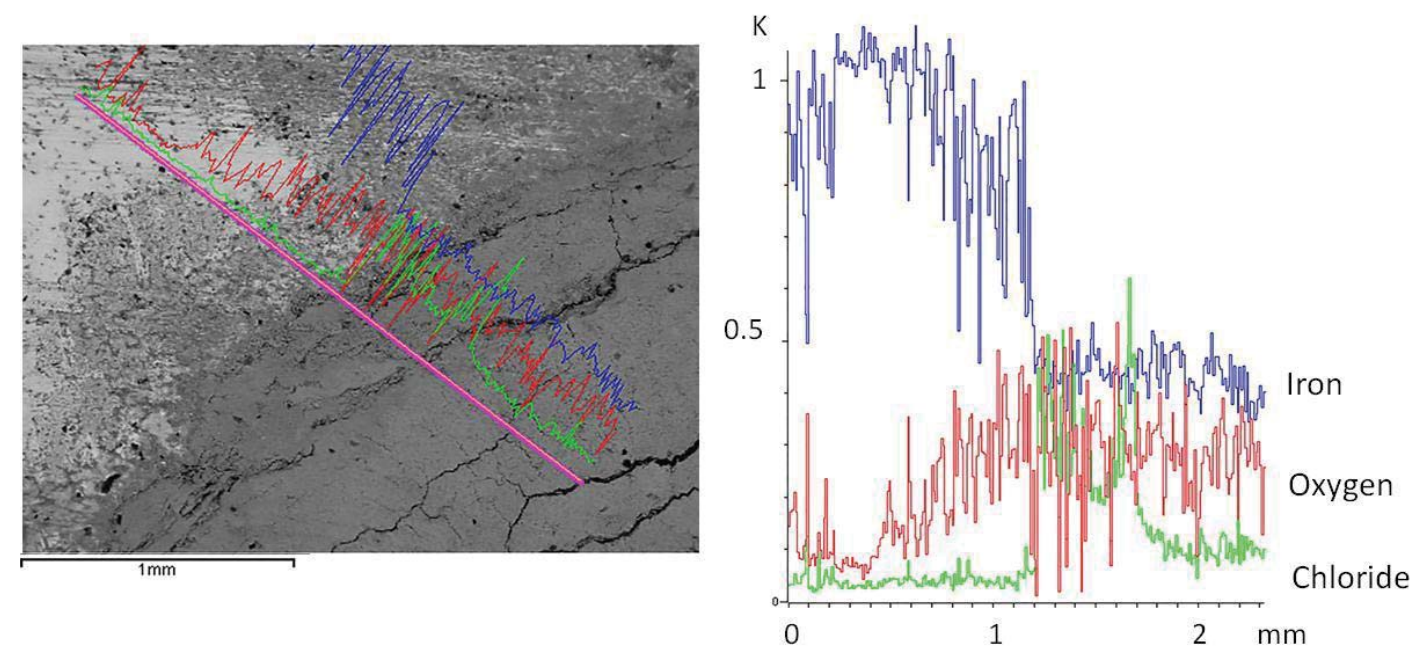

Fig.18. Scan of steel/oxide interface. The figure on the right shows a detail of the relative contents of the elements studied 


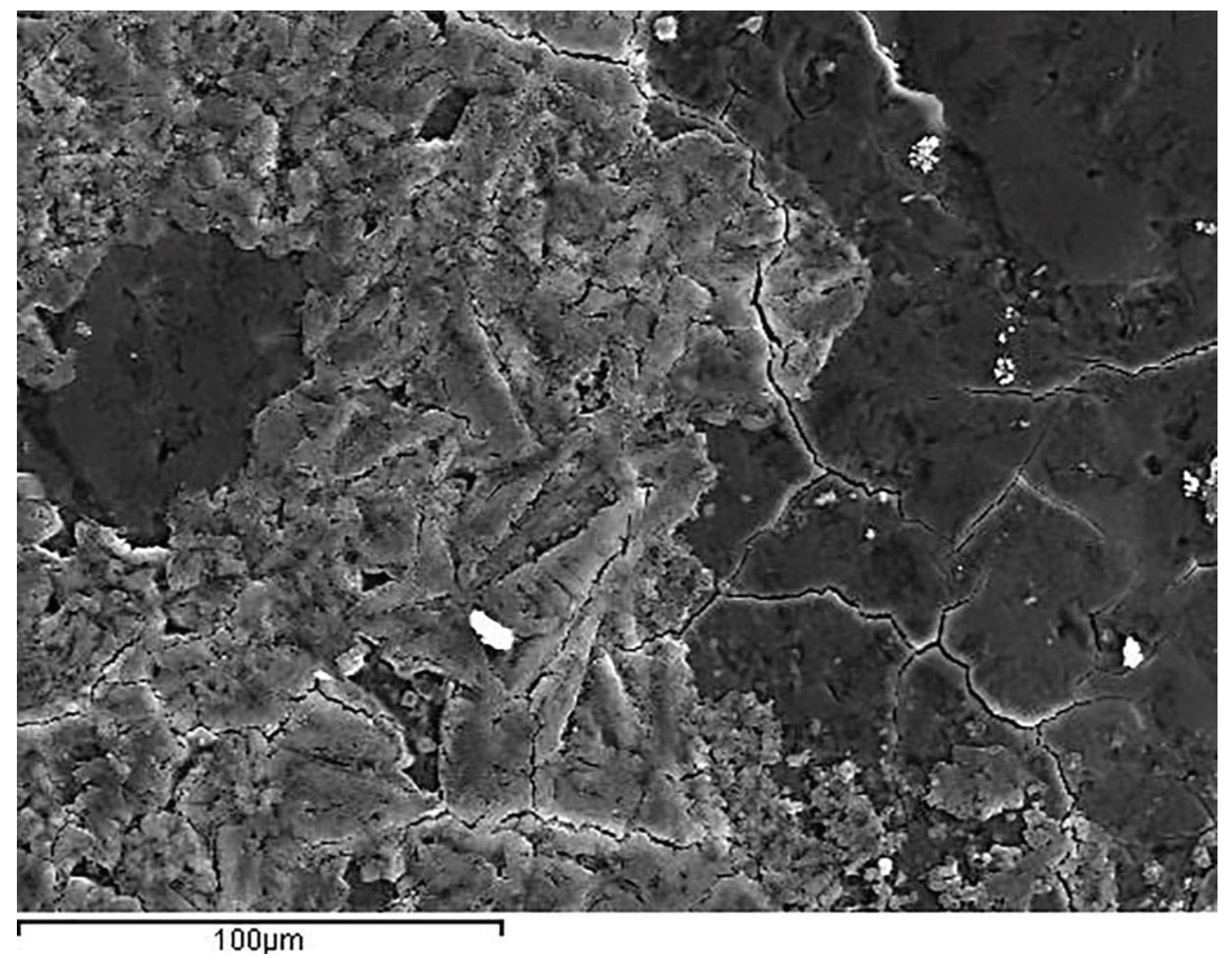

Fig.19. Morphology of oxides in a corroded zone 


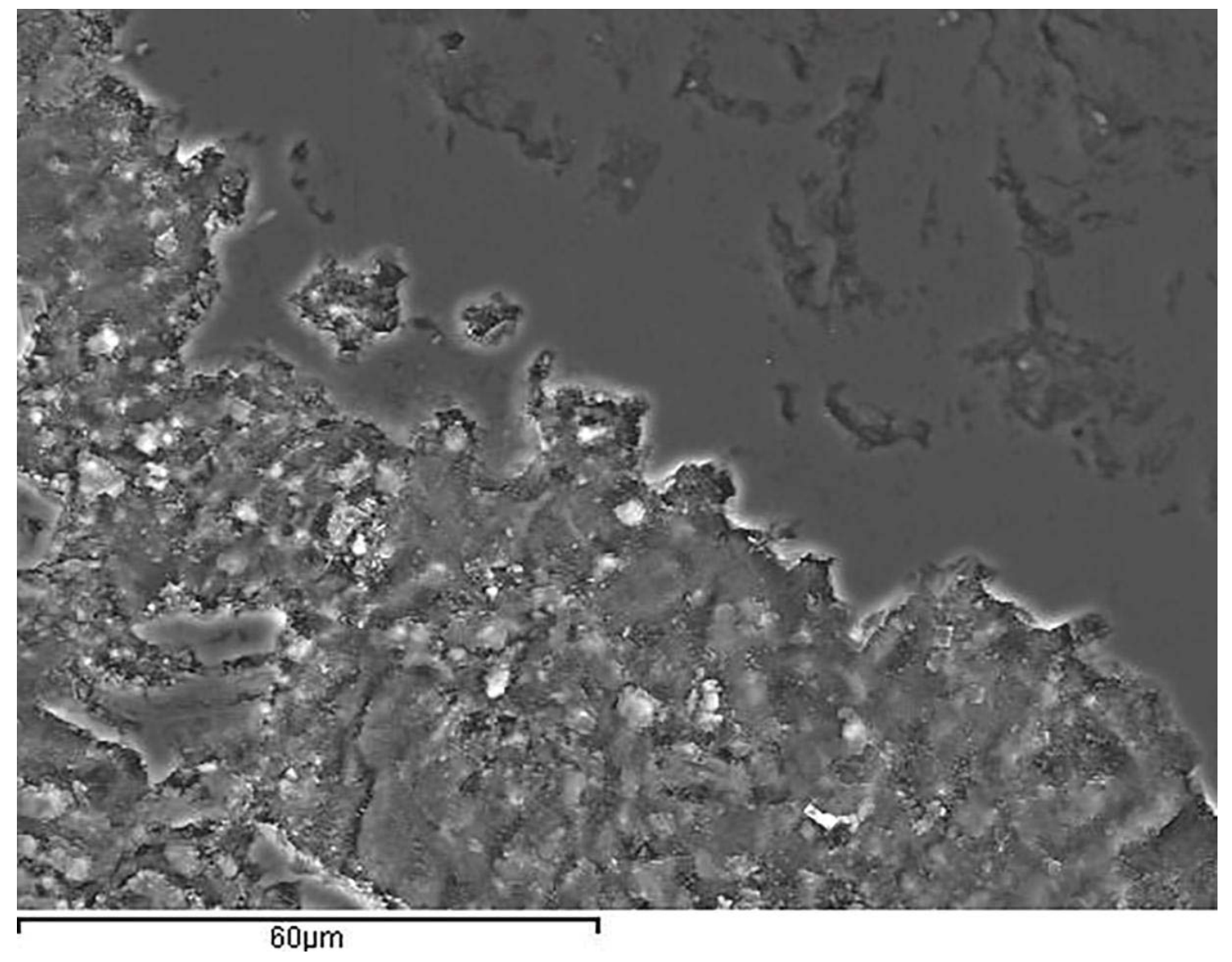

Fig.20 Morphology of oxides in a corroded zone 

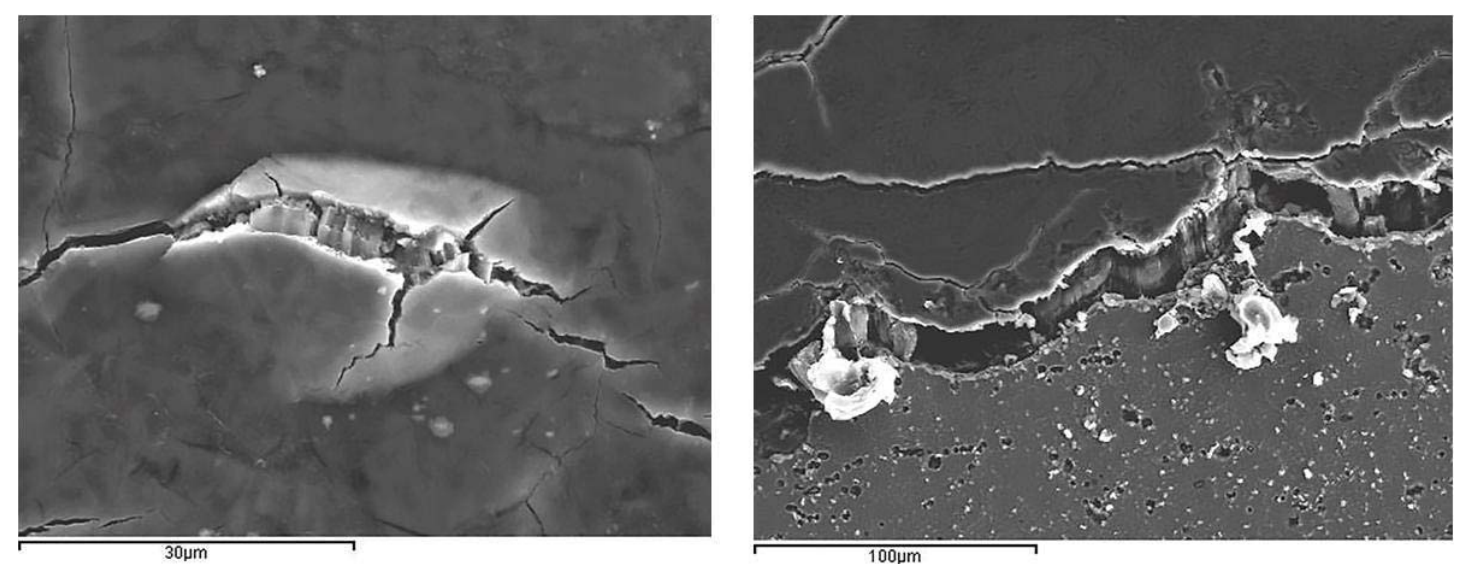

Fig 21. Detail of cracks showing different oxide expansion rates 
$\mathbf{a}$

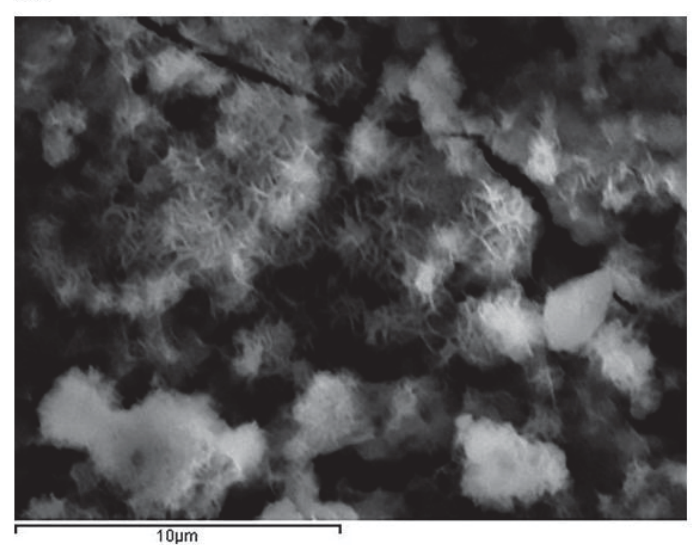

b

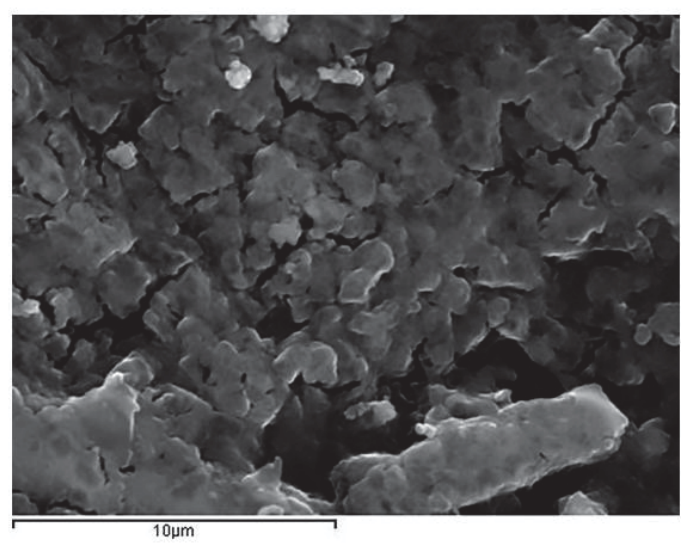

Fig.22. Morphology of oxides in pitting of column reinforcement rebars. a) Crystalline formations found in zones with highest concentration of chloride ions; b) formations in zones with lowest concentrations of chloride ions. 


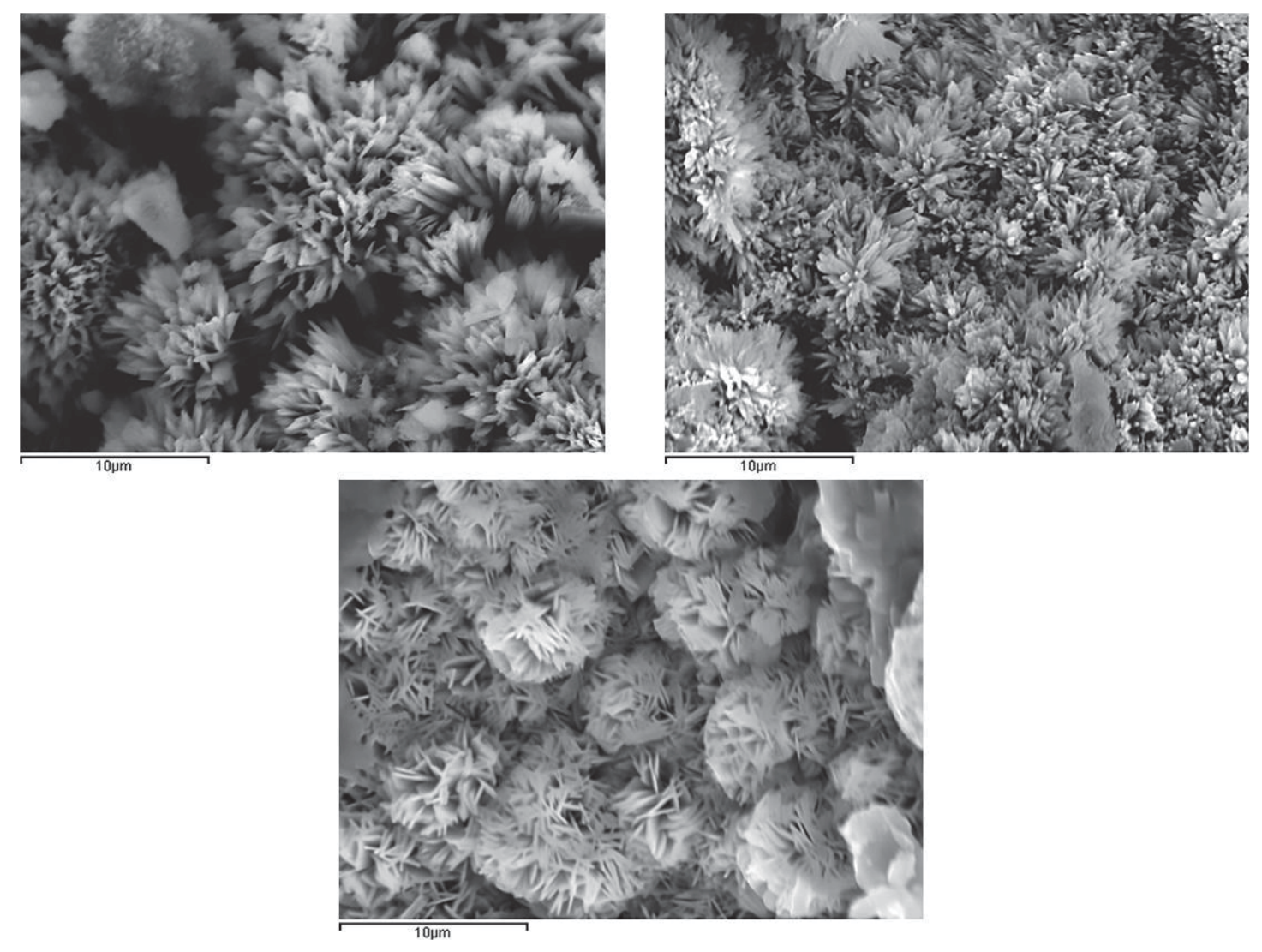

Fig.23. Morphology of oxides in column reinforcement rebars and joist wires 

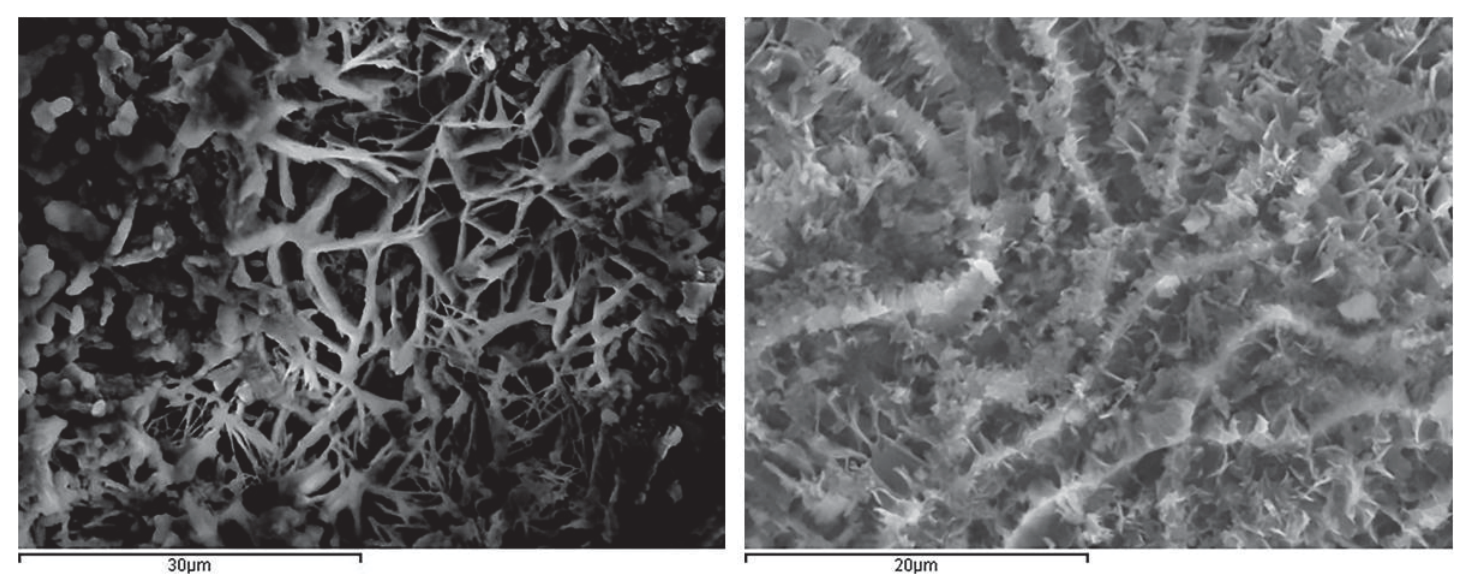

Fig. 24. Morphology of oxides in joist wires 

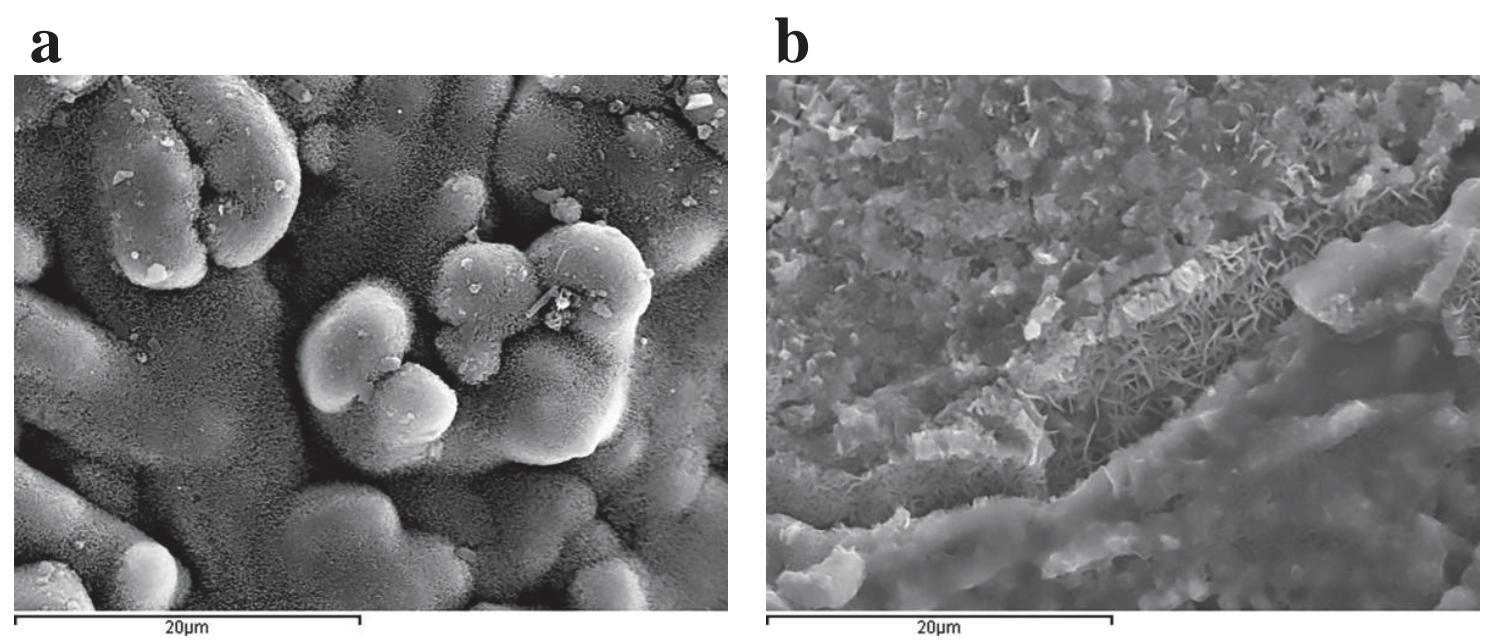

Fig. 25. Formations of oxides in rebars (3000x). a) Presence of magnetite and goethite b) typical goethite crystals 


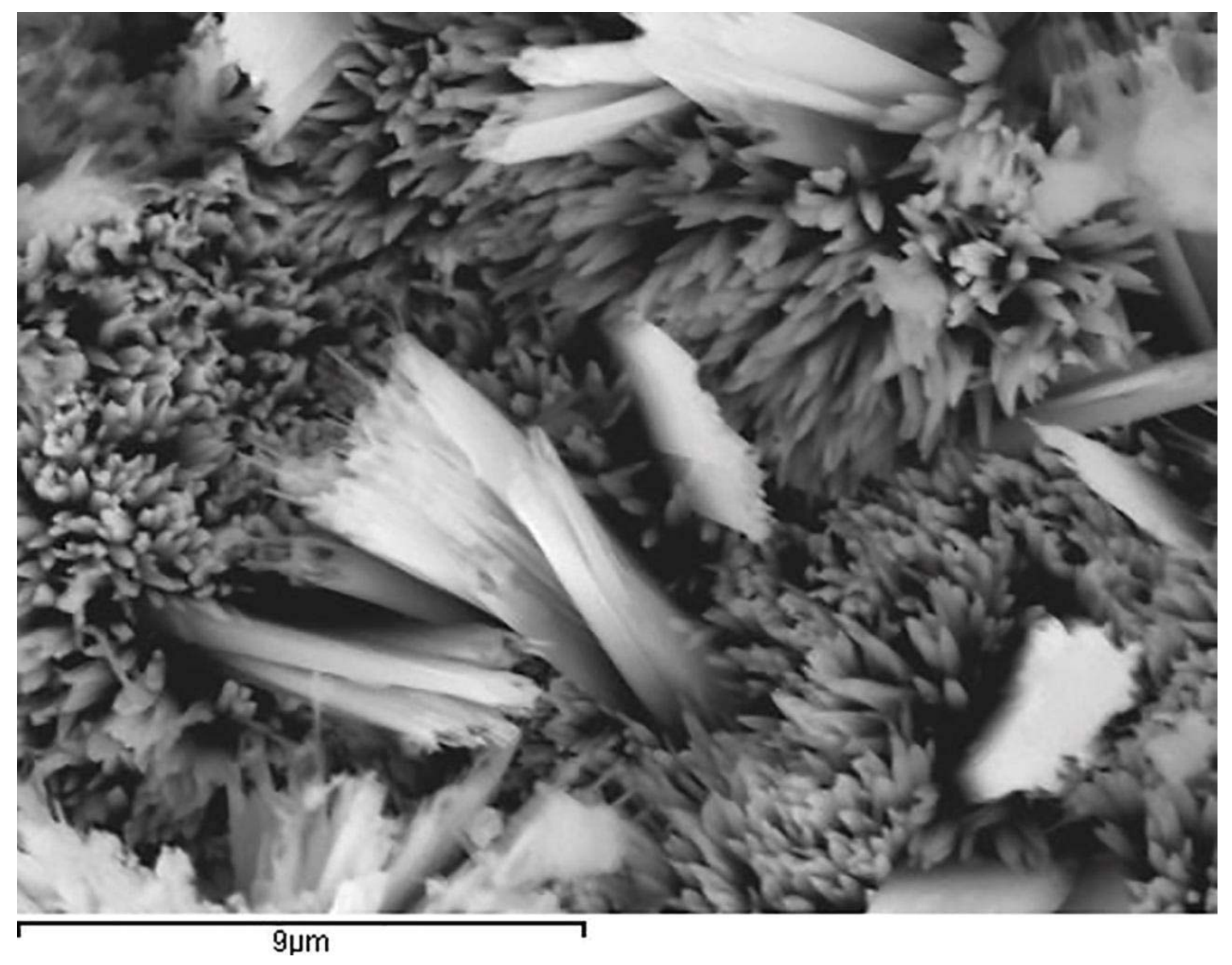

Fig.26. Morphology and EDX analysis of FeO in joist wire 